\title{
Oxidative Stress Regulation on Endothelial Cells by Hydrophilic Astaxanthin Complex: Chemical, Biological, and Molecular Antioxidant Activity Evaluation
}

\author{
M. Zuluaga, ${ }^{1}$ A. Barzegari, ${ }^{2}$ D. Letourneur, ${ }^{1}$ V. Gueguen, ${ }^{1}$ and G. Pavon-Djavid ${ }^{1}$ \\ ${ }^{1}$ INSERM U1148, Laboratory for Vascular Translational Science, Cardiovascular Bioengineering, Paris 13 University, Sorbonne Paris \\ Cité 99, Av. Jean-Baptiste Clément, 93430 Villetaneuse, France \\ ${ }^{2}$ Research Center for Pharmaceutical Nanotechnology, Tabriz University of Medical Sciences, Daneshgah Street, \\ Tabriz 51656 65811, Iran
}

Correspondence should be addressed to G. Pavon-Djavid; graciela.pavon@univ-paris13.fr

Received 8 May 2017; Revised 20 July 2017; Accepted 24 July 2017; Published 27 September 2017

Academic Editor: Silvana Hrelia

Copyright (c) 2017 M. Zuluaga et al. This is an open access article distributed under the Creative Commons Attribution License, which permits unrestricted use, distribution, and reproduction in any medium, provided the original work is properly cited.

An imbalance in the reactive oxygen species (ROS) homeostasis is involved in the pathogenesis of oxidative stress-related diseases. Astaxanthin, a xanthophyll carotenoid with high antioxidant capacities, has been shown to prevent the first stages of oxidative stress. Here, we evaluate the antioxidant capacities of astaxanthin included within hydroxypropyl-beta-cyclodextrin (CD-A) to directly and indirectly reduce the induced ROS production. First, chemical methods were used to corroborate the preservation of astaxanthin antioxidant abilities after inclusion. Next, antioxidant scavenging properties of CD-A to inhibit the cellular and mitochondrial ROS by reducing the disturbance in the redox state of the cell and the infiltration of lipid peroxidation radicals were evaluated. Finally, the activation of endogenous antioxidant PTEN/AKT, Nrf2/HO-1, and NQOI gene and protein expression supported the protective effect of CD-A complex on human endothelial cells under stress conditions. Moreover, a nontoxic effect on HUVEC was registered after CD-A complex supplementation. The results reported here illustrate the need to continue exploring the interesting properties of this hydrophilic antioxidant complex to assist endogenous systems to counteract the ROS impact on the induction of cellular oxidative stress state.

\section{Introduction}

While reactive oxygen-derived species are the product of normal aerobic metabolism, they can also be produced at elevated rates under pathophysiological conditions [1]. As a consequence an alteration in the redox signaling leads to uncontrolled reactions between free radicals and neighboring molecules such as proteins, lipids, nucleic acids, and carbohydrates, inducing an imbalance in the redox homeostasis $[2,3]$ and thus originating a range of abnormalities further associated with chronic diseases. The apparition of abnormalities associated with vascular diseases was shown to be related with ROS production in the vessel wall [4]. Carotenoids like antioxidants have been investigated due to their capacity to moderate the damaging effects of ROS [5]. According to Britton [6], to be an effective antioxidant, carotenoids must react with free radicals in order to inhibit formation of harmful products by disrupting free radical chain reactions. Additionally, carotenoids can serve as a lipid peroxyl radical quenching either by the addition or abstraction of a hydrogen atom, or by electron transfer [7]. Tapiero et al. [8] attributed the singlet molecular oxygen and peroxyl radical scavenger action against photooxidative process to carotenoids.

An important aspect to bear in mind is that some carotenoids can switch from antioxidants to prooxidants. Among the factors that may trigger such change are the excessive increase of carotenoid concentration, high partial pressure of oxygen and oxidative stress which speeds up ROS production, and the capacity of carotenoids to interact and localize within membranes [9]. Besides the toxic effect carried out by high carotenoid concentration, controlled amounts may 


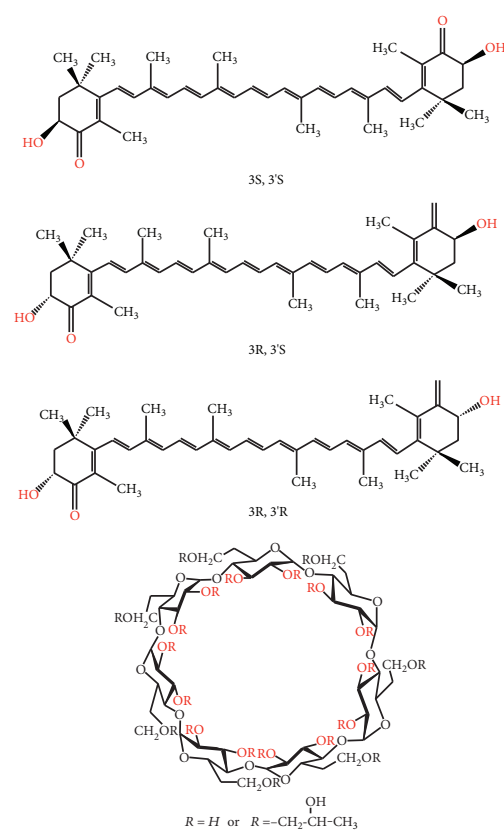

(a)

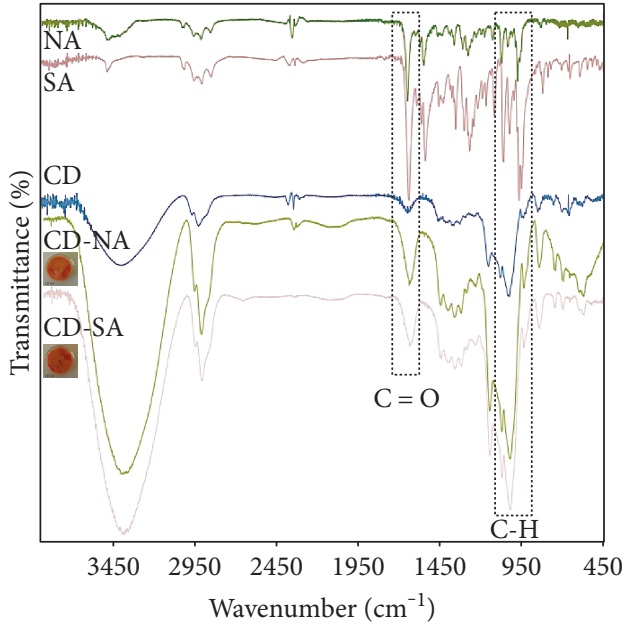

(b)

FIGURE 1: CD-A complex characterization. (a) Chemical structure of astaxanthin: 3S, $3^{\prime} S$; 3R, 3'S; 3R, 3'R esterification and hydroxypropyl- $\beta$ cyclodextrin (CD), respectively. (b) FT-IR spectrums of NA, SA, CD, CD-NA, and CD-SA.

lead to the activation of signaling pathways able to recognize potential threats [10], particularly the Nrf2 transcription factor, in which antioxidants are believed to exert an indirect action [11].

Astaxanthin, a xanthophyll carotenoid, shows interesting and strong antioxidant and anti-inflammatory properties $[12,13]$. Among the available sources of astaxanthin, two are of relevant importance: the natural (from microalgae Haematococcus pluvialis) and the produced via chemical synthesis. In the present work, both sources of astaxanthin in free form (without esterification) and purified by highperformance liquid chromatography, containing different stereoisomers, were used. Synthetic astaxanthin presents the isomers $3 R, 3^{\prime} R^{\prime}, 3 S, 3^{\prime} S$, and $3 R, 3^{\prime} S$ while $3 S, 3^{\prime} S$ is the only stereoisomer present in the natural source, Figure 1(a) [14-16]. Different antioxidant activities of both astaxanthin have been reviewed [17].

Owing to its structure, astaxanthin acts not only as a chain-breaking scavenger of free radicals but also as an inhibitor of lipid peroxidation [18]. In contrast to beta-carotene, the polar characteristics of astaxanthin allow it to preserve the membrane structure showing a significant antioxidant activity while avoiding a prooxidant effect $[19,20]$. Additionally, the indirect antioxidant capacity of astaxanthin was also shown to potentially contribute to the regulation of gene expression [21-23]. As a highly unsaturated molecule, astaxanthin has a low water solubility and can be easily degraded by light, oxygen, and temperature, leading to the decrease of its bioavailability and a diminution of its properties [24]. Coombes et al. reported the natural astaxanthin plasma absorption up to $0.19 \mu \mathrm{mol} / \mathrm{L}$ into the blood after 1 to $12 \mathrm{mg}$ human intake for 1 year. The authors did not found significant effect on the oxidative stress reduction after oral ingestion in renal transplant recipients and suggested that the lack of effect could be due to the lower doses or to the length of the treatment [25].

At exposed by Forman et al., low antioxidant bioavailability could be convenient in order to prevent these molecules from acting as prooxidants; however, encapsulation systems, besides being a limitation to this regard, protect the molecule externally before ingestion to avoid further degradations [10]. Among the encapsulation strategies attempted for astaxanthin protection [26-29], the molecular inclusion with cyclodextrins has shown interesting results regarding astaxanthin solubility and stability [30, 31]. This research focused on the direct and indirect evaluation of the protective effect of hydroxypropyl- $\beta$-cyclodextrin-astaxanthin (CD-A) complex on human endothelial cells under exogenous oxidative stress. The synthesis and characterization of CD-A complex was successfully achieved. To verify the correct encapsulation of astaxanthin within the system and the sensitivity of this new complex to oxidation, direct, $\mathrm{CD}-\mathrm{A}$ radical scavenging was quantified using $\mathrm{AAPH}$, $\mathrm{ABTS}^{\bullet+}$, and $\mathrm{DPPH}^{\bullet}$ assays after in tube generation of

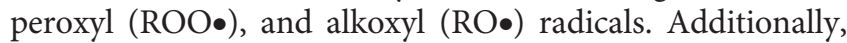
in vitro tests allow the evaluation of CD-A complex interaction with target molecules such as protein side chain, unsaturated fatty acid, and other reactive oxygen species after $\mathrm{t}-\mathrm{BuOOH}$ stress induction $[32,33]$. Superoxide radical production was generated after mitochondrial depolarization after induction by antimycin A, thus blocking the electron transfer [34], while lipid peroxyl radicals were initiated by addition of Cumene hydroperoxide (CumOOH) [35]. An indirect antioxidant capacity evaluation was performed 
by understanding the molecular mechanisms involved in the regulation of endothelial cell gene expression by CD-A complex.

\section{Materials and Methods}

2.1. Chemical Reagents. Synthetic astaxanthin (SA; purity $>97.3 \%$, powder, Lot: 40816) was purchased from Dr. Ehrenstorfer Co. Ltd. (LGC Standards, Germany). Natural astaxanthin (NA; purity $>97 \%$ HPLC, powder, Lot: $5 \mathrm{M} 4707 \mathrm{~V})$, hydroxypropyl- $\beta$-cyclodextrin (CD; DS =0.67), MitoTEMPO (SML0737; >98\% HPLC), N-acetyl-L-cysteine (NAC; A9165), and antimycin A (Streptomyces sp.) were purchased from Sigma-Aldrich Co. LLC (Saint Louis, MO, USA); as well as the antioxidant standard 6-hydroxy2,5,7,8-tetramethylchroman-2-carboxylic acid (Trolox, Lot: BCBJ8170V), 2,2' -azino-bis(3-ethylbenzothiazoline-6-sulfonic acid) diammonium salt (ABTS, Lot: 061M538V), potassium persulfate ( $\geq 99 \%$, Ref: 216224$)$, Cumene hydroperoxide ( $\geq 99 \%$, Ref: 247502$)$, 3-(4,5-dimethyl-2-thiazolyl)2,5-diphenyl-2H-tetrazolium bromide (MTT), tert-butyl hydroperoxide $(t$-BuOOH, Lot: BCBJ2885V), 2,2' -azobis(2methylpropionamidine) dihydrochloride (AAPH, Ref. 440914), fluorescein (Ref. F6377), 2,2-diphenyl-1-picrylhydrazyl (DPPH, Ref: D9132), Power SYBR Green Master Mix (ABI Biosystem, Ref: 4472908), dimethyl sulfoxide (DMSO, Lot: SZBD1830V), and isopropanol (70\% in $\mathrm{H}_{2} \mathrm{O}$, Ref: 563935). 5-(and 6-)Chloromethyl-2', $7^{\prime}$-dichlorodihydrofluorescein diacetate, acetyl ester $\left(\mathrm{CM}-\mathrm{H}_{2} \mathrm{DCFDA}\right.$, Lot: 1600227) and C11-BODIPY ${ }^{\circledR}$ 581/591 (Lipid Peroxidation Sensor, D3861) were purchased from Life Technologies (Invitrogen, Eugene, OR, USA). MitoSOX Red was purchased from Thermo Fisher Scientific (Oregon, USA). Acetone (HPLC gradient grade), methanol (HPLC gradient grade), and chloroform (HPLC gradient grade) were purchased form Carlo Erba Reagents S.A.S (France). Cell culture reagents were all purchased from Gibco (Life Technologies, Carlsbad, CA, USA). Double distilled and deionized water was used for all the experimentation process.

2.2. Preparation of $C D-A$ Complex. Natural and synthetic astaxanthin (NA and SA) were included into CD according to the method presented by previous authors $[30,36]$, with minor modifications. Briefly, $1 \mathrm{~mL}$ of NA or SA in acetone/chloroform ( $v / v \quad 1: 1)$ solution $(1 \mathrm{mg} / \mathrm{mL})$ was added to $250 \mathrm{mg}$ of CD dissolved in $12.5 \mathrm{~mL}$ of $95 \%$ methanol $(20 \mathrm{mg} / \mathrm{mL})$ in a $25 \mathrm{~mL}$ flask filled with nitrogen. The mixture was sonicated ( 5 min Ultrasonic bath BANDELIN SONOREX RX-100-H) and stirred for $24 \mathrm{~h}$ at $35^{\circ} \mathrm{C}$ in a dark chamber. Subsequently, the solution was subjected to a vacuum concentrator and recovered with distilled water. The final solution was frozen, lyophilized (Cryotec, Lyophilizer Crios, Saint Gely du Fesc, France), and stored at $-4^{\circ} \mathrm{C}$.

2.3. Characterization of $C D-A$ Complex. To establish the astaxanthin content into the complexes, a calibration curve of SA $(5 \mathrm{mg} / 10 \mathrm{~mL}$ DMSO) absorbance at $480 \mathrm{~nm}$ was plotted against concentrations $(0-20 \mu \mathrm{M}$; UV/VIS spectrophotometric measurements, Perkin Elmer Lambda 12 spectrophotometer). Once the curve was established, the complexes ( $5 \mathrm{mg} / 1 \mathrm{~mL}$ DMSO) were analyzed by UV/VIS spectroscopy and the concentration and inclusion rate of astaxanthin into the complex were calculated according to Chen et al. [30] as seen in 1. Where $C_{\text {astaxanthin }}$ is the astaxanthin content in the inclusion complex $(\mathrm{g} / \mathrm{mL}) ; W_{i}$ is the total weight $(\mathrm{g})$ of inclusion complex; $V_{c}$ is the volume $(\mathrm{mL})$ of the solvent used for quantification analysis; $W_{a}$ is the weight of astaxanthin (g) used for inclusion complex preparation; and $W_{c}$ is the weight of complex (g) used for quantification.

$$
\text { Inclusion rate }(\%)=\frac{C_{\text {astaxanthin }}{ }^{*} W_{i}^{*} V_{c}}{\left(W_{a}^{*} W_{c}\right)^{*} 100} .
$$

FT-IR characterization corroborates the astaxanthin inclusion within CD. A homogenized powder was obtained by mixing a sample of CD-NA or CD-SA with $200 \mathrm{mg}$ of $\mathrm{KBr}$. Then, each mix powder was placed into a sampling cup, smoothed, and compressed into the holder using a compression gauge. The obtained compact mixture was placed into the IR spectrometer (AVATAR 370, Thermo Spectra Tech Inc., Shelton, CT, USA), and spectral curves in the ranges of $400-4000 \mathrm{~cm}^{-1}$ were recorded using OMNIC Software (Thermo Fisher Scientific Inc., Waltham, MA, USA).

\subsection{Direct CD-A Antioxidant Activity Measurement}

2.4.1. Trolox Equivalent Antioxidant Capacity (TEAC) Assay. Antioxidant capacities of CD-NA and CD-SA complexes were measured using the TEAC assay protocol presented by Re et al. [37] with slight modifications. Here, the ABTS radical cation $\mathrm{ABTS}^{\bullet+}$ is obtained by the oxidation of ABTS $(7 \mathrm{mM})$ with potassium persulfate $\left(\mathrm{K}_{2} \mathrm{~S}_{2} \mathrm{O}_{8}, 2.45 \mathrm{mM}\right)$ in distilled water (vol/vol reaction). The resulting solution was placed in the dark at room temperature for $12-16 \mathrm{~h}$ before use. CD-NA, CD-SA $(0-5 \mu \mathrm{M}, 50 \mu \mathrm{L})$, or Trolox standards $(0-200 \mu \mathrm{M}, 50 \mu \mathrm{L})$ were mixed with $1 \mathrm{~mL}$ of $\mathrm{ABTS}^{\bullet+}$ (absorbance maximum of $0.70 \pm 0.02$ at $734 \mathrm{~nm}$ ). The absorbance of the mixture solution was recorded after $1 \mathrm{~h}$ of incubation at $30^{\circ} \mathrm{C}(734 \mathrm{~nm}$, UV/VIS Lambda 12 , PerkinElmer Inc., Norwalk, CT, USA). Inhibition percentage was calculated using 2 . The Trolox equivalent antioxidant capacity (TEAC) was defined as the millimolar concentration of Trolox with the same antioxidant activity as $1 \mathrm{mM}$ concentration of the samples [38].

$$
\text { Scavenging rate }(\%)=\frac{\left[\mathrm{ABTS}^{+}\right]_{\text {initial }}-\left[\mathrm{ABTS}^{+}\right]_{\text {final }}}{\left[\mathrm{ABTS}^{+}\right]_{\text {initial }}} * 100
$$

2.4.2. The Oxygen Radical Antioxidant Capacity (ORAC) Assay. The oxygen radical antioxidant capacity of CD-NA and CD-SA complexes was evaluated $[32,39]$. Fluorescein solution $(4 \mathrm{nM}, 150 \mu \mathrm{L})$ was mixed with CD-NA $(0-5 \mu \mathrm{M}$, $25 \mu \mathrm{L})$, CD-SA $(0-5 \mu \mathrm{M}, 25 \mu \mathrm{L})$, Trolox standards $(1-18 \mu \mathrm{M}$, $25 \mu \mathrm{L})$ or blanks, and AAPH $(160 \mathrm{mM}, 25 \mu \mathrm{L})$ in a $96-$ well microplate. The plate was incubated at $37^{\circ} \mathrm{C}$, and fluorescence decay was monitored during $1 \mathrm{~h}$ with data taken every minute using an emission/excitation filter of 
485-528 nm (i-control ${ }^{\mathrm{TM}}$ microplate reader software, TECAN Männedorf, Switzerland). The complex antioxidant activity was determined from its ability to keep the fluorescence signal of the indicator in the presence of peroxyl radicals. The AUC and $\mathrm{AUC}_{\text {net }}$ were calculated using 3 and 4 . Where $f_{1}$ is the initial fluorescence reading at $0 \mathrm{~min}$ and $f_{\mathrm{i}}$ is the fluorescence measured at time $i$. Final ORAC values were calculated by using the regression equation between the Trolox concentration and the $\mathrm{AUC}_{\text {net }}$ and were expressed as Trolox equivalents (TEAC) as millimolar per liter.

$$
\begin{aligned}
\mathrm{AUC} & =0.5+\left(\frac{f_{2}}{f_{1}}\right)+\left(\frac{f_{3}}{f_{1}}\right)+\cdots+0.5\left(\frac{f_{n}}{f_{1}}\right) . \\
\mathrm{AUC}_{\text {net }} & =\mathrm{AUC}_{\text {sample }}-\mathrm{AUC}_{\text {blank }} .
\end{aligned}
$$

2.4.3. CD-A Antioxidant Activity by DPPH. CD-A complex antioxidant activity was evaluated using the DPPH-free radical assay [40]. Briefly, DPPH $(0.16 \mathrm{mM} ; 1.5 \mathrm{~mL})$ was added to $2 \mathrm{~mL}$ of different sample CD-A complexes $(0-5 \mu \mathrm{M})$, Trolox standards, or blank in ethanol solution. The mixture was incubated for $30 \mathrm{~min}$ in the dark at $25^{\circ} \mathrm{C}$. Antioxidant effect was evaluated by following the decrease of UV absorption at $517 \mathrm{~nm}$. The radical scavenging activity was calculated using 5. Where $A_{c}$ is the DPPH solution absorption, $A_{i}$ is the DPPH solution absorption after sample addition, and $A_{j}$ is the initial absorption of the experimental samples.

$$
\text { Scavenging rate }(\%)=\frac{A_{c}-\left(A_{i}-A_{j}\right)}{A_{c}} * 100 \text {. }
$$

2.5. Cell Culture. Human umbilical vein endothelial cells (HUVECs) were purchased from ATCC (CRL 1730). Cells were grown in minimum essential medium-L-glutamine (MEM), supplemented with $10 \%(v / v)$ fetal calf serum (FBS) and 1\% penicillin-streptomycin-amphotericin (PSA). Cells were seeded in a T75 cell culture flask (Corning) and kept in a humidified incubator containing $5 \% \mathrm{CO}_{2}$ at $37^{\circ} \mathrm{C}$. The culture medium was replaced twice every week, and the cells were split $1: 3$ every week.

2.6. Evaluation of CD-A Cytotoxicity in HUVEC by MTT Reduction Assay. Cell viability was assessed using MTT assay. Briefly, HUVEC density of $2.10^{4}$ cells/well was seeded and cultured overnight. Cells were treated with different samples: CD-NA and CD-SA $(0-5 \mu \mathrm{M})$, any antioxidant (culture medium MEM, negative toxicity control, NTC), or $10 \%$ DMSO (positive toxicity control, PTC) during $24 \mathrm{~h}$ or $48 \mathrm{~h}$. Afterwards, all solutions were washed and cells were incubated during $3 \mathrm{~h}$ at $37^{\circ} \mathrm{C}$ with $200 \mu \mathrm{L}$ of MTT solution $(0.5 \mathrm{mg} / \mathrm{mL})$. Then, all wells were washed out of MTT solution and $200 \mu \mathrm{L}$ of isopropanol were added for $20 \mathrm{~min}$ to solubilize the formazan crystals. The optical density was recorded at $490 \mathrm{~nm}$ (i-control microplate reader software, TECAN Männedorf, Switzerland). Not cytotoxicity of samples was considered if cellular viability was $>70 \%$ of the control (based on the ISO 10993:2009 regarding the biological evaluation of medical devises).
2.7. In Vitro Inhibition of Cellular Reactive Oxygen Species and Lipid Peroxidation by CD-A Complex. The capacity of CD-NA and CD-SA complexes to reduce the cellular levels of ROS and lipid peroxides in human endothelial cells was determined using the fluorescence probes $\mathrm{CM}-\mathrm{H}_{2} \mathrm{DCFDA}$, MitoSOX Red, and C11-BODIPY, respectively. Prior to tests, HUVECs were removed from growth media and detached with trypsin after reached the $80 \%$ of confluence. A density of $1.10^{4}$ cells/well was seeded in a 96-well cell culture plates and incubated overnight at $37^{\circ} \mathrm{C}$ with $5 \% \mathrm{CO}_{2}$. Low glucose-MEM was used to prepare antioxidant samples: CD-NA and CD-SA samples $(0-5 \mu \mathrm{M})$, NAC $(500 \mu \mathrm{M})$, and MitoTEMPO (500 nM). Hank's buffered salt solution (HBSS) was used to solubilize the probes.

2.7.1. Cellular ROS Measurement. Cellular antioxidant activity of CD-NA and CD-SA complexes was quantified using the cell permeable probe $\mathrm{CM}-\mathrm{H}_{2} \mathrm{DCFDA}$. This probe emits no fluorescence in its original state. After crossing the cell membrane, DCFH-DA is hydrolyzed by intracellular esterases into DCFH, which becomes fluorescent once oxidized to DCF in the presence of ROS. The accumulation of DCF inside the cells is measured by the fluorescence increase at $530 \mathrm{~nm}$ using an excitation wavelength of $485 \mathrm{~nm}$ in a kinetic mode [41]. HUVECs were incubated overnight with medium containing CD-NA $(5 \mu \mathrm{M}), \mathrm{CD}-\mathrm{SA}(5 \mu \mathrm{M})$, or reference antioxidants NAC $(500 \mu \mathrm{M})$, and MitoTEMPO $(0.5 \mu \mathrm{M})$. After $24 \mathrm{~h}$, the cells were washed twice with PBS to remove the medium and $\mathrm{CM}-\mathrm{H}_{2}$ DCFDA was added to the wells $(5 \mu \mathrm{M}$ final concentration) during $1 \mathrm{~h}$, under light protection. Oxidative stress was induced by the subsequent addition of t-BuOOH $(100 \mu \mathrm{M})$ or antimycin A $(200 \mu \mathrm{M}$, during $20 \mathrm{~min}$ ), excluding the blank wells. Variations in the fluorescence intensity were recorded during $60 \mathrm{~min}$ with data taken every $5 \mathrm{~min}$ (i-control microplate reader software, TECAN Männedorf, Switzerland). The capacity of CD-A to reduce the oxidative cell environment was evaluated as expressed in (6), where $I_{c n}$ and $I_{s n}$ represent the intensity of cells exposed to $\mathrm{t}-\mathrm{BuOOH}$ or antimycin $\mathrm{A}$ without and with antioxidant presence at time $n$, respectively.

$$
\operatorname{CAA}(\%)=\frac{I_{c n}-I_{s n}}{I_{c n}} * 100 \text {. }
$$

2.7.2. Mitochondrial ROS Detection. The capacity of CD$\mathrm{NA}$ and CD-SA complexes to inactivate mitochondrial superoxide production was measured using MitoSOX Red fluorescent probe. MitoSOX Red after being target to the mitochondria, it is oxidized by superoxide to form 2hydroxymitoethidium [42]. HUVECs were incubated overnight with medium containing CD-NA $(5 \mu \mathrm{M})$, CD-SA $(5 \mu \mathrm{M})$, or reference antioxidants NAC $(500 \mu \mathrm{M})$, and MitoTEMPO $(0.5 \mu \mathrm{M})$. After $24 \mathrm{~h}$, the cells were washed twice with PBS to remove the medium and incubated with MitoSOX $(5 \mu \mathrm{M})$, for 20 minutes at $37^{\circ} \mathrm{C}$, protected from light. Cells were gently washed three times with warm buffer. Reactive oxygen species were induced by the addition of antimycin A (AA; $200 \mu \mathrm{M}$, during $20 \mathrm{~min}$ ), excluding the blank wells. Fluoresce was monitored at $\lambda \mathrm{ex} / \lambda \mathrm{em}=510 / 595 \mathrm{~nm}$ 
(single-read measure; i-control microplate reader software, TECAN Männedorf, Switzerland). CD-A effect in decreasing mitochondrial ROS generation was compared to the percentage of control (not stressor or antioxidant treatment).

2.8. Cellular Lipid Peroxidation Analysis. C11-BODIPY581/ 591 is a fluorescent fatty acid analogue which allows the quantification of lipid peroxidation by indirect measure of mitochondrial ROS production [43]. Upon free radicalinduced oxidation, its fluorescent properties shift from red to green [44]. Ninety-six well plates containing the cells were washed with PBS, before addition of C11-BODIPY $(5 \mu \mathrm{M}$, during $30 \mathrm{~min}$ ). Cells were incubated with $5 \mu \mathrm{M}$ of CD-NA and CD-SA for $1 \mathrm{~h}$, under light protection. Lipid peroxidation was initiated by addition of Cumene hydroperoxide (CumOOH, $50 \mu \mathrm{M})$. Fluoresce was monitored at red $\lambda \mathrm{ex} /$ $\lambda \mathrm{em}=590 / 7,632 / 45 \mathrm{~nm}$ and green $\lambda \mathrm{ex} / \lambda \mathrm{em}=485 / 14,520 /$ $10 \mathrm{~nm}$ (i-control microplate reader software, TECAN Männedorf, Switzerland). Percent of CD-A cellular lipid peroxide activity inhibition was calculated relative to the positive control fluorescence intensity (PC; $\mathrm{CumOOH}$ without antioxidant).

\subsection{Indirect $C D-A$ Antioxidant Activity Measurement}

2.9.1. mRNA Extraction and Real-Time RT-PCR. HUVECs were seeded in 6 -well plates. Then, CD-A $(8 \mu \mathrm{M})$ was added to the cells and incubated for $24 \mathrm{~h}$. After discarding the supernatant, the cells were washed twice with PBS and incubated with AAPH $(5 \mathrm{mM})$ or t-BuOOH $(25 \mu \mathrm{M})$ for $24 \mathrm{~h}$ (the IC50 of AAPH and or $\mathrm{t}-\mathrm{BuOOH}$ at $24 \mathrm{~h}$ were determined $5 \mathrm{mM}$ and $25 \mu \mathrm{M}$, resp., (data not showed)). Total RNA was extracted using the TRIzol ${ }^{\circledR}$ reagent (Invitrogen TM, Life Technologies). The RNA yield and purity were determined using a NanoDrop ND-1000 spectrophotometer. For RTPCR, $1 \mu \mathrm{g}$ of RNA, $0.4 \mu \mathrm{m}$ universal hexamer primer, $1 \mu \mathrm{L}$ dNTP $(10 \mathrm{Mm})$, and DEPC water mixed and incubated at $65^{\circ} \mathrm{C}$ for $5 \mathrm{~min}$ and kept on ice. Then, $5 \mathrm{U}$ reverse transcriptase enzyme (MMLV), 1x RT buffer, and $1 \mathrm{U} / \mu \mathrm{L}$ RNase inhibitor were added to reaction and the solution was increased to a volume of $20 \mu \mathrm{L}$ with DEPC water. Reverse transcription of mRNAs was performed at $25^{\circ} \mathrm{C}$ for $10 \mathrm{~min}$ and $42^{\circ} \mathrm{C}$ for $60 \mathrm{~min}$. Then, real-time PCR was performed to measure expression levels of target genes (Table 1) using a power SYBR Green Master Mix (ABI Biosystem) on a Bio-Rad IQ5 real-time PCR detection system.

2.9.2. Immunoblotting. Proteins were extracted from the treated HUVEC using radioimmunoprecipitation assay buffer (RIPA, $50 \mathrm{mM}$ Tris-base, $1.0 \mathrm{mM}$ EDTA, $150 \mathrm{mM}$ $\mathrm{NaCl}, 0.1 \%$ SDS, $1 \%$ Triton $\mathrm{X}-100,1 \%$ sodium deoxycholate, and $1 \mathrm{mM}$ phenylmethylsulfonyl fluoride). Extracts were separated by $12 \%$ SDS-PAGE gel and transferred to a polyvinylidene difluoride membrane (Millipore, MA, USA) previously probed with primary antibodies (Abcam) specific to NQO1 (ab80588), PTEN (ab137337), HO-1 (ab52947), Nrf2, and GAPDH (ab37168) before being incubated with horse radish peroxidase-conjugated secondary antibody (1:2000, Sigma-Aldrich). Bands were detected using a chemiluminescent kit (ECL, Thermo, 32106). Experiments were performed in triplicate.

2.10. Statistical Analysis. All experiments were repeated at least three times to ensure the reproducibility of each test. The results were expressed as the mean \pm SDE, and statistical analysis was done using one-way ANOVA followed by Tukey's HSD post hoc test (JMP Software, Version 9; SAS Institute, Cary, NC, USA). The results were considered significantly different if $p$ value $<0.05$.

For real-time PCR, the level of expression was calculated based upon the PCR cycle number $\left(C_{T}\right)$. The endogenous control GAPDH and RNU6 were used for normalization of mRNA and microRNA expression levels, respectively. $C_{T}$ values were used to calculate relative expression using SPSS Version 14.0 software by difference in the $C_{T}$ values of the target RNAs after normalization to RNA input level. Relative quantification was represented by standard $2^{\Delta \mathrm{CT}}$ calculations. $\Delta C_{T}=\left(C_{T \text {-target gene }}-C_{T \text {-GAPDH }}\right)$. Each reaction was performed in triplicate.

\section{Results and Discussion}

3.1. Characterization of $C D-A$ Complex. Here, both natural and synthetic astaxanthin were successfully included into the CD hydrophobic cavity (Figure 1, SD available online at https://doi.org/10.1155/2017/8073798), showing that stereoisomers did not constrain the inclusion process, as confirmed by FTIR measurements. Figure 1(b) presents the representative absorption bands of astaxanthin at $1656-1652 \mathrm{~cm}^{-1}$, and 974-970 $\mathrm{cm}^{-1}$, which indicate the $\mathrm{C}=\mathrm{O}$ and $\mathrm{C}-\mathrm{H}$ stretching vibrations respectively; after $\mathrm{CD}$ inclusion, these bands were weaker, as reported by Qiu et al. [45].

According to the regression model suggested by Dong et al. [36], an inclusion rate of $12.05 \pm 0.96 \%$ for CD-NA and $7.21 \pm 0.64 \%$ in the case of CD-SA was obtained, with a weight recovery rate around $89 \%$ (Figure S1A-B). CD-NA and CD-SA concentrations after inclusion were $3.4 \pm 0.4 \mu \mathrm{M}$ and $2.6 \pm 0.4 \mu \mathrm{M}$, respectively, calculated from the SA calibration curve and the CD-A OD curves at $480 \mathrm{~nm}$ (Figure S1C-D). No astaxanthin precipitation was noticed even when solubilized with high amounts of CD-A complex in DI water, which is in accordance with similar works [31, 46-48].

3.2. CD-A Antioxidant Quantification. Oxidative stress is produced by the action of different ROS; hence, efficient methods able to quantify the influence of external substances like antioxidants in the prevention of radical's formation are needed. Available indirect probes provide valuable information on changes on the redox environment of the cell, but many of these methods are not specific and do not allow subcellular localization, and their response is affected by different chemical interactions [49]. Despite that, these methods represent a valuable tool to obtain an overview of the antioxidant ability of several molecules such as antioxidants.

The antioxidant activity of CD-NA and CD-SA complexes was directly assessed by TEAC, DPPH, and ORAC assays. These chemical methods, while being simple, 
TABLE 1: The sequences of primers used for study of profile of RNAs using q-PCR.

\begin{tabular}{|c|c|c|c|}
\hline Target genes & Primer & Primer sequence $\left(5^{\prime}-3^{\prime}\right)$ & Annealing temperature $\left({ }^{\circ} \mathrm{C}\right)$ \\
\hline \multirow{2}{*}{ PTEN } & Forward & TCCCAGTCAGAGGCGCTATG & \multirow{2}{*}{60} \\
\hline & Reverse & CACAAACTGAGGATTGCAAGTTC & \\
\hline \multirow{2}{*}{ Nrf2 } & Forward & GAGACAGGTGAATTTCTCCCAAT & \multirow{2}{*}{59} \\
\hline & Reverse & TTTGGGAATGTGGGCAAC & \\
\hline \multirow{2}{*}{$\mathrm{HO} 1$} & Forward & ACGGCTTCAAGCTGGTGATG & \multirow{2}{*}{61} \\
\hline & Reverse & TGCAGCTCTTCTGGGAAGTAG & \\
\hline \multirow{2}{*}{ NQOI } & Forward & ATGTATGACAAAGGACCCTTCC & \multirow{2}{*}{62} \\
\hline & Reverse & TCCCTTGCAGAGAGTACATGG & \\
\hline \multirow{2}{*}{ Bax } & Forward & ATCCAGGATCGAGCAGGGCG & \multirow{2}{*}{64} \\
\hline & Reverse & GGTTCTGATCAGTTCCGGCA & \\
\hline \multirow{2}{*}{ AKT1 } & Forward & GTTTGCCGGAATCAATTTTC & \multirow{2}{*}{60} \\
\hline & Reverse & AGCCAGAGCTGTGATCTCCTT & \\
\hline \multirow{2}{*}{ GAPDH } & Forward & GAGCCAAAAG GGTCATCATC & \multirow{2}{*}{63} \\
\hline & Reverse & TAAGCAGTTGGTGGTGCAGG & \\
\hline \multirow{2}{*}{ Caspase-3 } & Forward & TGTGAGGCGGTTGTGGAAGAGT & \multirow{2}{*}{63} \\
\hline & Reverse & AATGGGGGAAGAGGCAGGTGCA & \\
\hline \multirow{2}{*}{ eNOS } & Forward & ATCTCCGCCTCGCTCATG & \multirow{2}{*}{61} \\
\hline & Reverse & GAGCCATACAGGATTGTCGC & \\
\hline
\end{tabular}

sensitive, and reproducible, provide useful information about the carotenoid antioxidant activity [50]. CD-NA and CD-SA scavenging capacities corresponded to $5.73 \pm 2.9$ and 3.93 $\pm 2.8 \mathrm{mM}$ of Trolox, respectively, (Figure 2(a)), evaluated by the $\mathrm{ABTS}^{\bullet+}$ assay. This result agreed with TEAC values reported by other authors for astaxanthin in its free form $[39,51-54]$. ORAC assay was used to measure the capacity of CD-NA and CD-SA to inhibit the thermal decomposition of AAPH against alkyl $(\mathrm{R} \bullet)$, peroxyl (ROO•), and alkoxyl (RO•) radicals, (where $R=\mathrm{H} 2 \mathrm{~N}(\mathrm{HN}) \mathrm{C})$ [32, 39]. Here, ORAC values $(5.73 \pm 2.1$ and $5.10 \pm 3.10 \mathrm{mM}$ of Trolox $)$ were in the same range as those obtained by $\mathrm{ABTS}^{\bullet+}$ assay (Figure 2(c)). It seems appropriate to refer to the scavenging capacities reported for esterified astaxanthin and synthetic astaxanthin, which according to the literature are in a range between $0.1 \pm 0.25$ and $2.43 \pm 0.02$ for natural and synthetic astaxanthin, respectively, using the ABTS assays and $1.68 \pm$ 0.25 and $8.1 \pm 1.12$ using ORAC test $[51,53,54]$. The variability of these capacities could probably be due to the low miscibility of hydrophilic components with chemical products. Additionally, the preservation of CD-A antioxidant capacity was evaluated after 6 months of complex storage at $6^{\circ} \mathrm{C}$ under light protection. Figure $2(\mathrm{~d})$ presents an ORAC TEAC value in the order of $5 \mathrm{mM}$ of Trolox for both CDNA and CD-SA complexes, reflecting the successful conservation of astaxanthin in the CD cavity. Passed this time, a floc was observed in the vials, a behavior already described by Chen et al. [30], who observed a floc formation after $6 \mathrm{~h}$ of complex dispersion in water. However, the preservation of astaxanthin antioxidant capacity after 6 months revealed that even if astaxanthin precipitates, a new covalent bond could be induced by simply mixing the vial.
Regarding the DPPH radical quenching, an inhibition percentage around $18 \%$ was found for CD-A complex at astaxanthin concentration of $5 \mu \mathrm{M}$, a not negligible value, since literature reported scavenging rate of $97 \%$ for a greater SA concentration $(133 \mu \mathrm{M})$ [55]. Here, we report a complex inhibition capacity against ROS directly reliant to the astaxanthin concentration within the complex. CD-NA and CD-SA complexes presented a similar antioxidant scavenging capacity as expressed by the TEAC value; however, their activity was stronger than the Trolox standard antioxidant molecule, evaluated by ABTS $^{\bullet+}$ and ORAC assays. No significant difference was observed between astaxanthin radical quenching before and after inclusion into the CD and Trolox, in the DPPH test. Some authors attribute the antioxidant capacity of astaxanthin, to the activation of the hydroxyl group by the keto group allowing the hydrogen transfer to the peroxyl radical, and thus acting as a chain breaking in the free radical reaction $[56,57]$. The astaxanthin inclusion into the CD cavity took place due to a noncovalent link between the CD hydrophobic cavity and the hydrophobic molecule, enhancing the CD-drug interaction with the lipophilic environment [58], without affecting the antioxidant properties.

In this study, chemical probes were used in principle as a verification tool of the preservation of CD-A complex sensitivity to oxidation before the evaluation of biological antioxidant capabilities. However, authors want to recognize the variability and instability of these probes due to external factors like light, temperature, or $\mathrm{pH}$, which can degrade the probe during the time of analysis. Despite the use of a reference antioxidant Trolox and expressing the results based on Trolox equivalents, obtained results using ORAC, TEAC, and DPPH assays may lead to different conclusions, agreeing 


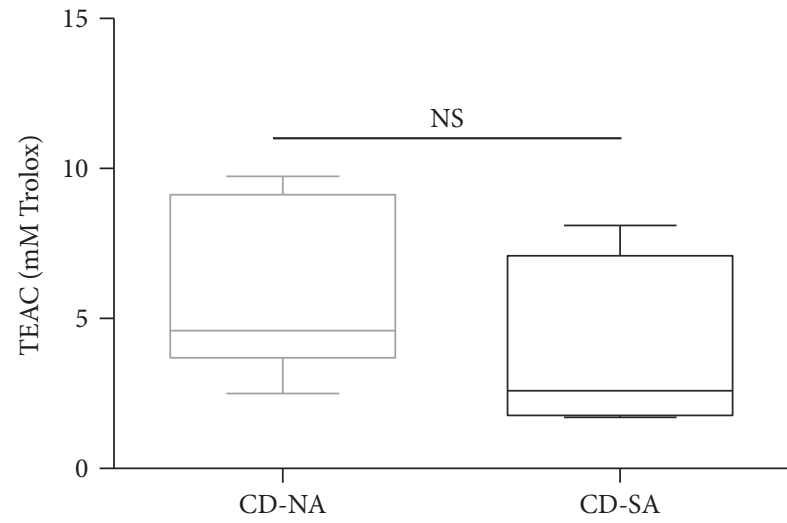

(a)

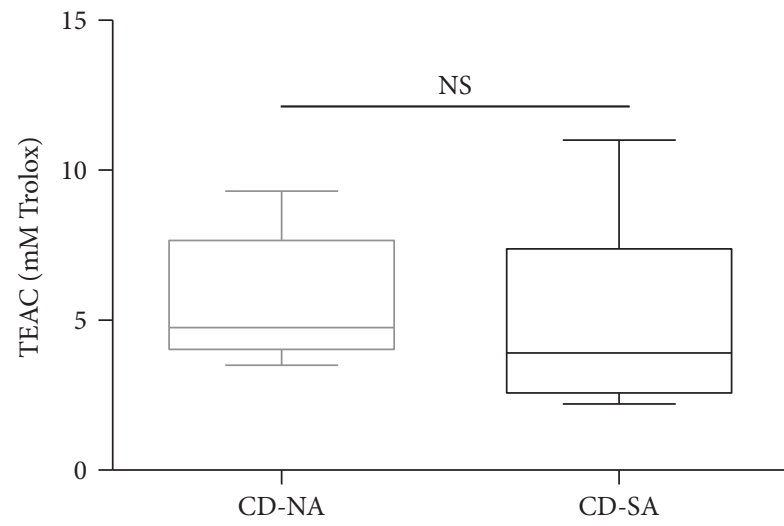

(c)

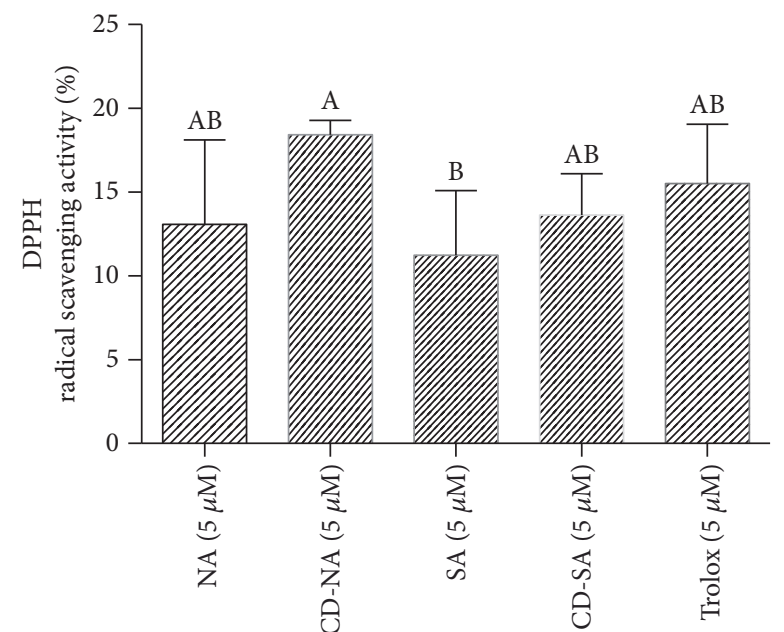

(b)

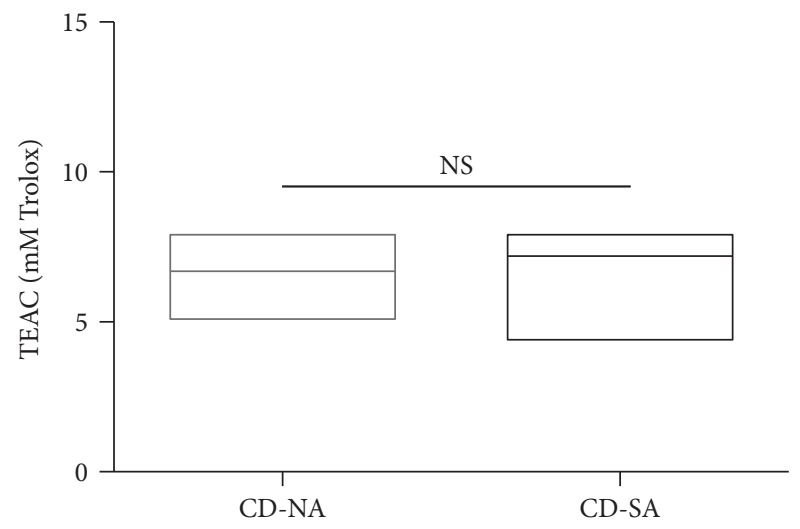

(d)

FIGURE 2: Chemical assays measuring the antioxidant capacity of CD-A complex. (a) TEAC CD-NA and CD-SA complexes measured by ABTS assay. (b) DPPH radical scavenging activity of free astaxanthin (NA and SA), CD-A complex, and Trolox antioxidant reference molecule. (c) Oxygen radical absorbance capacity (ORAC) assay of both complexes expressed as the Trolox equivalent in Mm. (d) CD-A complex antioxidant stability study after 6 months of storage at $6^{\circ} \mathrm{C}$, under light protection, calculated by means of ORAC assay. Data are means \pm SD of six experiments. Levels not connected by the same letter are significantly different $(p<0.05)$.

with data reported for some antioxidants [59]. It is worthy to highlight that $\mathrm{CD}-\mathrm{A}$ reacts differently with the reagents used in each test for the determination of its antioxidant capacity; moreover, its capabilities measured by these assays provide information about the chemical reactivity of these compounds to block ROS without referring to the in vitro or in vivo relevance on human health.

3.3. In Vitro Cytoprotective Activity of $C D-A$ Complex. CD have been currently used as a solubilizer for different kinds of hydrophobic molecules, and any up-to-date biocompatibility problem has been reported when exposed to diverse cell lines in concentrations not greater than $40 \mathrm{mg} / \mathrm{mL}$ [60-62]. Astaxanthin stability in culture medium is an important parameter conditioning cellular interaction and its antioxidant ability. Here, astaxanthin was included in CD complexes (CD-A) and thus stabilized in the culture medium at $37^{\circ} \mathrm{C}$. As shown in Figures 3(a) and 3(b), CD-A complexes were noncytotoxic to HUVEC, represented by a cell viability exceeding $70 \%$ at concentrations up to $5 \mu \mathrm{M}$ after 24 and $48 \mathrm{~h}$ of exposure, showing a good biological acceptance of the complex by the HUVEC. A maximum decay of $20 \%$ of NTC was registered for the CD-SA at concentrations higher than $5 \mu \mathrm{M}$, while CD-NA showed a faster decay at $2.5 \mu \mathrm{M}$ without exceeding $20 \%$ of NTC, indicating a suitable compatibility for both CD-A complex. These results agreed with the data reported for astaxanthin samples without inclusion, where a high cytoprotective potential was observed for concentrations lower than $25 \mu \mathrm{M}$ in a cell population of HUVEC, HepG2, and MCF-7 cells [51, 63]. Further, different $\mathrm{CD}$ concentrations were tested to verify their compatibility with HUVECs and no toxicity effects were remarked for concentrations lower than $40 \mathrm{mg} / \mathrm{mL}$ (data not shown).

3.4. Direct Biological Evaluation of CD-A Antioxidant Capability. In contrast to chemical assays which offer useful information of antioxidant activity of components, cellular tests take into account the bioavailability and metabolism of the tested compound providing information of ROS downstream effect in living cells [43]. Mechanisms of 


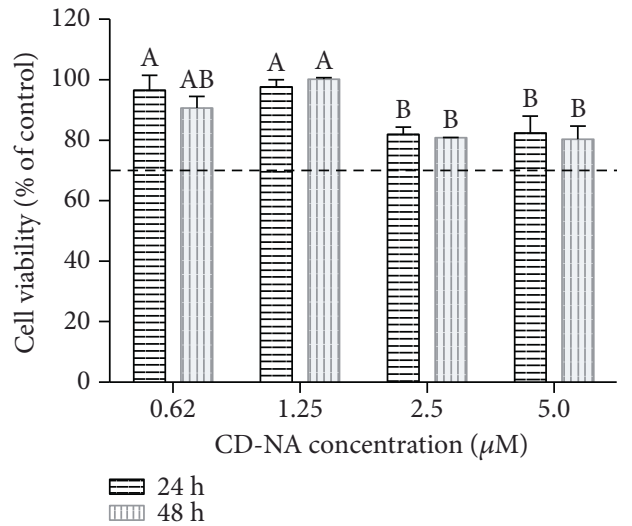

(a)

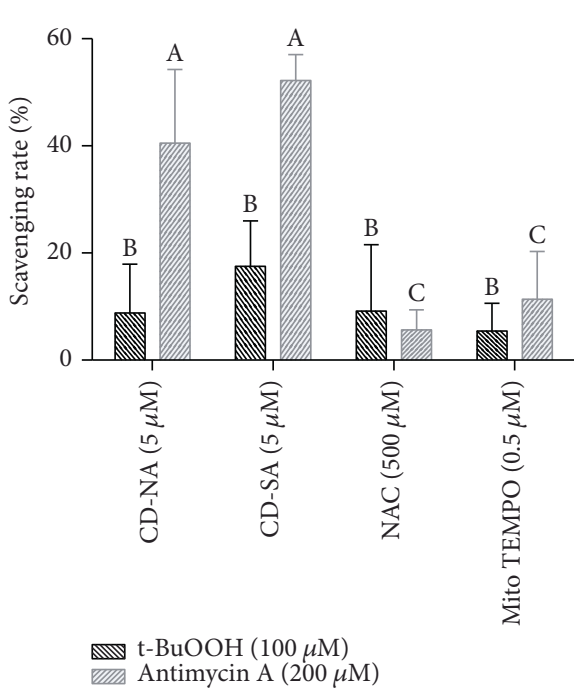

(c)

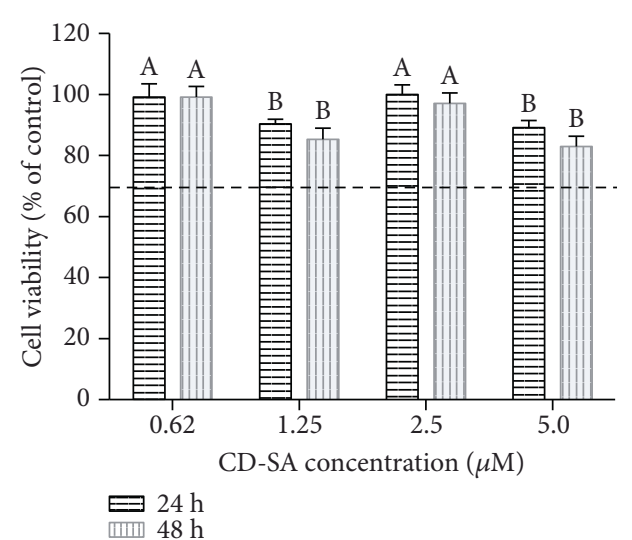

(b)

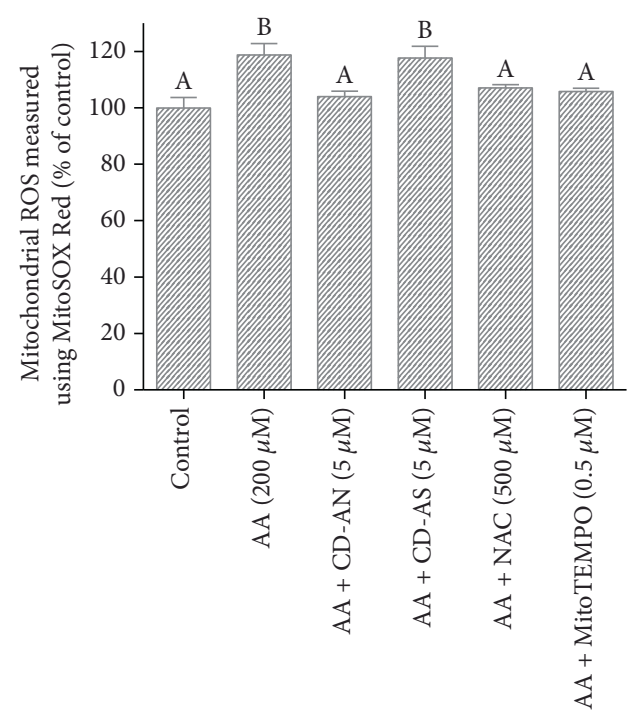

(d)

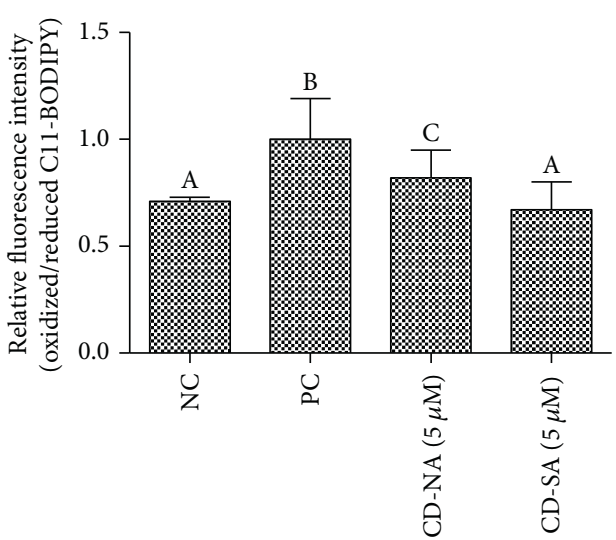

(e)

FIGURE 3: In vitro evaluation of CD-A complex cytocompatibility, CD-A complex protective effect against cellular ROS and lipid peroxidation. Cellular viability of HUVECs exposed to CD-A complex during (a) $24 \mathrm{~h}$ and (b) $48 \mathrm{~h}$ : doted lines represent a higher viability of $70 \%$ with regard to PTC (DMSO 10\%), indicating a good cell CD-A complex compatibility. Cellular antioxidant activity (CAA) of CDA complex measured by (c) $\mathrm{CM}-\mathrm{H}_{2}$ DCFDA and (d) MitoSOX Red: ROS were induced by either t-BuOOH or antimycin A in both assays. NAC and MitoTEMPO were used as antioxidant references. (d) Cellular lipid peroxidation activity (CLPAA) results for CD-A complex compared to positive control (HUVEC exposed to $\mathrm{CumOOH}$ ). Data are means \pm SD of six experiments. Levels not connected by the same letter are significantly different $(p<0.05)$. 
antioxidant/detoxifying protection are challenging. New approaches to detect ROS focused on the use of specific components to directly target organelles involve in ROS production. For instance, MitoSOX Red fluorescence probe is able to directly target complex III within the mitochondria to sense $\mathrm{O}_{2}^{--}$production, to form 2-hydroxy-mito-ethidium [42]. Also, C11-BODIPY probe assessed the indirect measure of mitochondrial ROS production in living cells to extent lipid peroxidation [44]. Moreover, the $\mathrm{CM}-\mathrm{H}_{2}$ DCFDA assay provided information concerning general disturbance in the redox state of cells [49]. In this study, several methods and stressors were used to assess biological relevance and cellular availability of astaxanthin to block oxidative stress.

Additionally, the direct scavenger capacity of CD-A to neutralize the chemical-induced oxidative stress in HUVEC after either peroxyl (ROO•) or alkoxyl $(\mathrm{RO} \bullet)$ radical generation using AAPH or $\mathrm{t}-\mathrm{BuOOH}$ was evaluated. Additionally, superoxide radicals were induced by antimycin $\mathrm{A}$, and lipid peroxyl radicals were initiated by addition of $\mathrm{CumOOH}$. CD-A complex scavenging capacity was compared with two antioxidants that were shown to protect endothelial cells under induced oxidative stress $[64,65]$ : (a) NAC, a scavenger of free radicals such as hydroxyl radical, hydrogen peroxide, and superoxide [66], and (b) MitoTempo, a mitochondriatargeted superoxide dismutase-specific antioxidant.

Intracellular antioxidant capacity of CD-A evaluated by CM- $\mathrm{H}_{2}$ DCFDA showed that HUVEC supplementation with either CD-NA or CD-SA during $24 \mathrm{~h}$ markedly inhibits superoxide radical induced by antimycin A. Scavenging rate of astaxanthin complexes (40-50\%) was higher than that measured after incubation with NAC or MitoTEMPO $(10-20 \%, p<0.05$; Figure 3(c)). Besides, RO• and ROO• radical reductions after $\mathrm{t}-\mathrm{BuOOH}$-induced stress were lower compared with CD-NA and CD-SA complexes (10-30\%), NAC or MitoTEMPO (5-20\%) treatments (nonsignificant differences). MitoSOX Red probe showed a significantly increased mitochondrial $\mathrm{O}_{2}^{--}$levels in HUVEC under antimycin A ROS induction (Figure 3(d), $p<0.05$ ). The redox equilibrium was reestablished after antioxidant supplementation (compared to nonstressed cells) showing similar levels for CD-NA, MitoTEMPO, and NAC (Figure 3(d)). Additionally, CD-A ability to protect HUVEC from lipid peroxidation was evaluated. Lipophilic C11-BODIPY probe was monitored as indicator of peroxidative membrane damages after addition of $\mathrm{CumOOH}$, a lipid peroxide radical initiator [22]. As showed in Figure 3(e), a reduction in the cellular lipid peroxidation state was observed when HUVECs were supplemented with CD-NA and CD-SA complexes. The astaxanthin capacity to inhibit the penetration of oxidative substances across the lipid membrane by blocking the initiation of a lipid peroxidation process was confirmed by other authors $[41,64]$. Here, we demonstrate the preservation of astaxanthin activity into the complexes.

Interestingly, intracellular antioxidant activities of CD$\mathrm{NA}$ and CD-SA complexes are higher than those reported for astaxanthin stereoisomers and free form without inclusion [51, 67-69]. Moreover, we previously showed the CAA protective capacity exerted by algae natural astaxanthin in human endothelial cells subjected to oxidative stress in vitro [51]. Recently, Xue et al. [70] demonstrated that astaxanthin treatment markedly attenuated mitochondrial ROS produced after total body irradiation. Moreover, a potent mitochondrial ROS reduction had been noticed when using targeted than nontargeted mitochondrial antioxidants in different in vitro and in vivo models [64, 70-74]. In contrast to synthetic astaxanthin, natural astaxanthin without purification also contains other carotenoids, and there is no much evidence confirming the fact that these carotenoids act in synergy, in an additive manner or possibly cancel each other [17]. The results showed here did not confirm or reject the anterior idea but support the fact that similar antioxidant activities are obtained for either natural or synthetic astaxanthin in free and purified form included within CD.

Efficient probes able to quantify antioxidant scavenging capabilities as well as ROS levels provide a key to understand antioxidants action mechanisms and to regulate the redox balance in the body (Figure 1). However, reactive species present some characteristics that make their detection difficult, like their very short lifetime and the endogenous antioxidant mechanism which regulate their levels in vivo [75]. Furthermore, the response of antioxidants to different radicals or oxidant sources vary widely [76]. The ideal chemical or biological probe would be highly reactive at low concentrations, specific, nontoxic, easy to use and to load into organelles, cells, or tissues without subsequent leakage, readily available and inexpensive $[49,77]$.

Up to now, there is not a unique probe filling all these criteria; therefore, the simultaneous use of chemical and biological methods is advised to obtain a better screening of the tested molecule properties. Chemical methods "in tube" provide a first approach to validate the antioxidant capacities of a specific component. On the other hand, biological methods allow measuring the antioxidant ability of a component to regulate the redox environment of an organelle and provide information about oxidative markers, intracellular antioxidant capacities, and endogenous antioxidant pathways [78].

Our results showed that the inclusion of astaxanthin within CD highly improved its lipid/aqueous affinity without affecting the intracellular antioxidant capacity against ROS. Moreover, positive antioxidant scavenging activities evidence astaxanthin cellular and mitochondrial targeted action to reduce the disturbance in the redox state of endothelial cells.

\subsection{Indirect $C D-A$ Antioxidant Protection against ROS}

3.5.1. CD-NA Protects Cells by Activation of Endogenous Antioxidant Systems by Nrf2/HO-1/NQO1 Pathway. Nrf2 (nuclear factor-erythroid 2-related factor 2) is a key transcription factor physiologically attached to Keap1 protein within the cytoplasm in basal conditions. Under oxidative stress, the Keap1-Nrf2 complex dissociates and Nrf2 translocates to the nucleus, inducing an endogenous antioxidant response of detoxifying enzymes and proteins such as heme oxygenase-

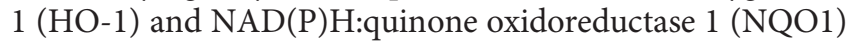
[78]. Heme oxygenase-1 (HO-1) is a stress response protein induced in response to a variety of oxidative challenges and pathological stimuli having cytoprotective function. HO-1 mediates the anti-inflammatory effects [79] and has a 

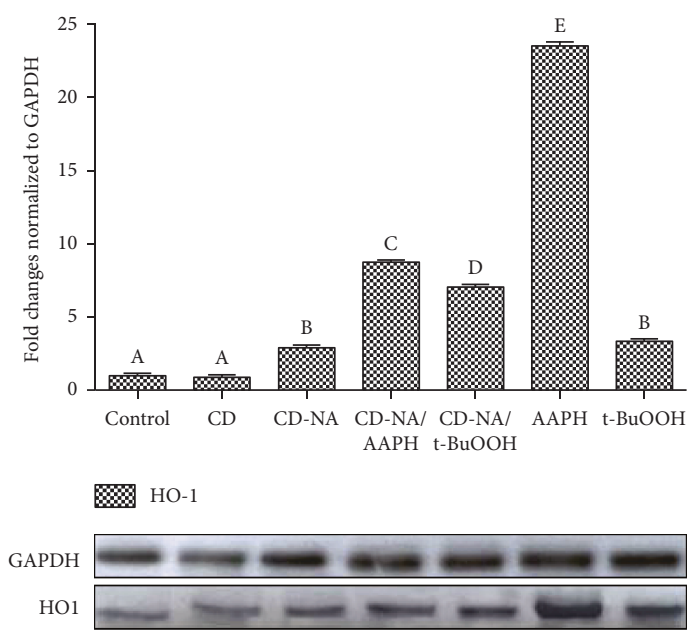

(a)

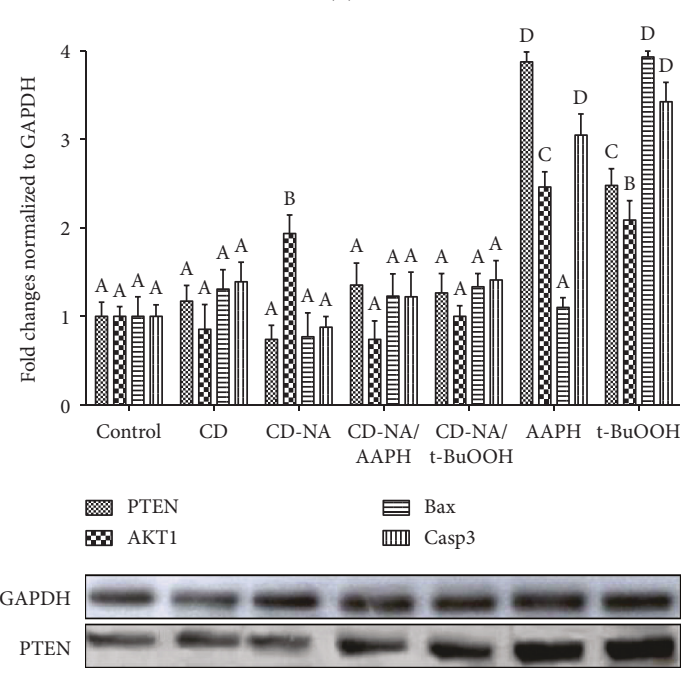

(c)

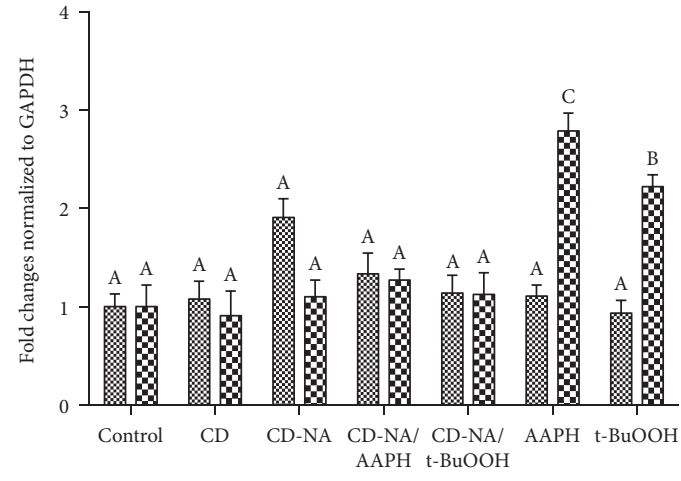

ख $\mathrm{Nrf2}$

\$ NQO1

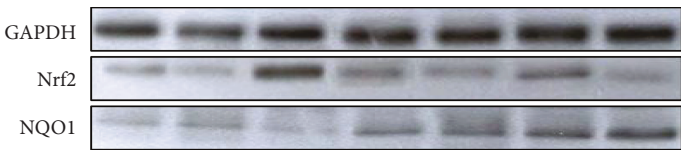

(b)

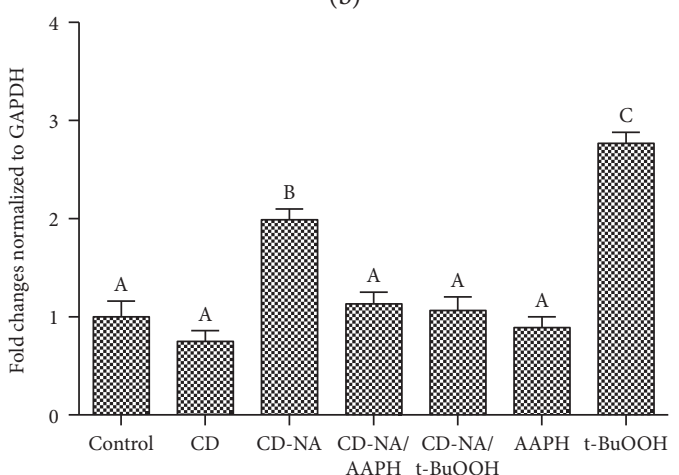

\% eNOS

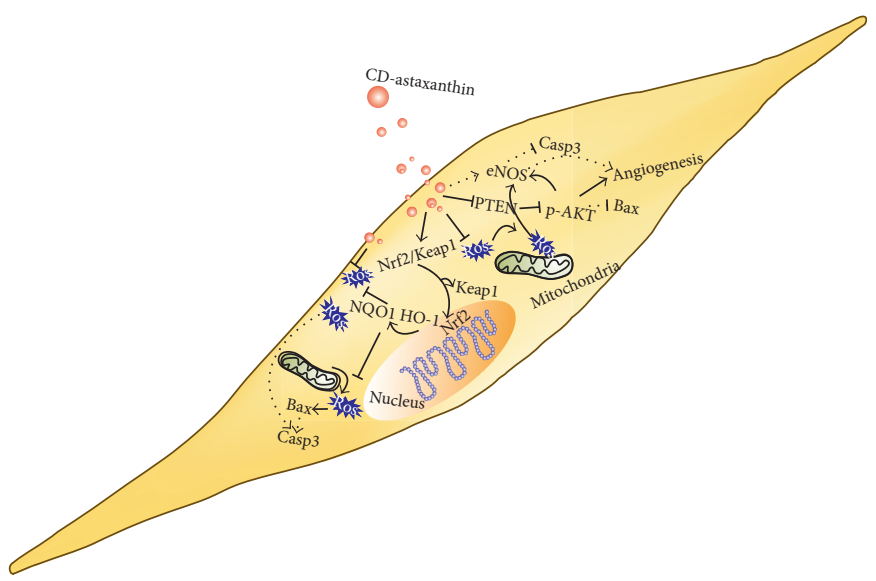

(e)

FIGURE 4: The molecular protection mechanism of CD-A complex against ROS. CD-A complex activates (a, b) Nrf2/HO-1/NQO1 and (c, d) PTEN/PI3K/AKT endogenous pathways. (e) Schematic representation of the molecular pathway of CD-A protective action on endothelial cells under oxidative stress. Levels not connected by the same letter are significantly different $(p<0.01)$. 
central role in cardiovascular protection [80]. NQO1 has an anti-inflammatory action and encodes for a reductase enzyme preventing the reduction of quinones that result in the production of radical species. Inflammatory cytokines that suppress NQO1 induce oxidative stress [81, 82]; mutations in this gene have been associated with cardiovascular disorders [83].

In this research, we studied CD-NA protective effect on human endothelial cells. Two different stressors were examined: $\mathrm{t}-\mathrm{BuOOH}$ and $\mathrm{AAPH}$, frequently used as a free radical donors which generate a burst of ROS, thus inducing the dissociation of Nrf2/Keap1 complex [33,84]. An overexpression of HO-1 and NQO1 was noticed when oxidative stress was induced in endothelial cells by both stressors (Figures 4(a) and 4(b)). The CD-NA cell treatments led to the upregulation of HO-1 and NQO1 basal expression and downregulation in ROS excess conditions. HO-1 and NQO1 protein expressions were analyzed after radical induction. A higher expression was detected when both stressors were present, while a similar upregulation trend using CD-NA complex was evidenced for both protein expressions (Figures 4(a) and 4(b)). In this study, the upregulation of HO-1 and NQO1 could be due to the separation of Nrf2/Keap1 by radical action, suggesting that in basal conditions, CD-NA allows Nrf2 gene upregulation. Moreover, Nrf2 gene expression was not affected after oxidative stress induction. The protein expression study confirmed these results (Figure 4(b)).

Astaxanthin action on $\mathrm{Nrf2/OH1/NQO1} \mathrm{pathway} \mathrm{was}$ previously described in vitro in animal cells; however, revealing results were conflicting $[22,85,86]$. Increased cellular GSH due to astaxanthin treatment on human hepatic cellular carcinoma cells (Huh7) was not mediated by an Nrf2dependent signal transduction pathway [87]. In contrast, Nrf2 was activated in human retinal pigment epithelial cells (ARPE-19) showing a reduction in the oxidative damage due to astaxanthin treatment [88]. Recently, Pan et al. showed that astaxanthin pretreatment significantly increased the expression of Nrf2, HO-1, and NQO1 mRNA in a cerebral ischemia rat model evidencing a protective effect against brain injuries [89]. The discrepancies between astaxanthinreported action could be related to differences in cellular type sensitivities upon carotenoid treatment, to the type of stress inducers, and to the astaxanthin product composition [17].

3.5.2. CD-NA Prevents Apoptosis of Endothelial Cells under Oxidative Stress by PTEN/PI3K/AKT Pathway. Previous studies revealed that intracellular ROS generation modulates the PTEN/PI3K/AKT pathway influencing the cell fate towards senescence and apoptosis [90]. AKT plays a vital role in vascular homeostasis, acting as a regulator of endothelial cell survival, growth, and NO production [91]. Astaxanthin was shown to protect in vivo isoflurane-induced neuroapoptosis in a rat model, supported by the diminution of brain damage, suppression of Casp3 activity, and upregulation the PI3K/AKT pathway [92]. In this study, ROS induction with $\mathrm{AAPH}$ and $\mathrm{t}-\mathrm{BuOOH}$ upregulates PTEN gene expression probably to deactivate the AKT, guiding cells to apoptosis (Figure 4(c)). Conversely, CD-NA treatment significantly reduces the PTEN expression in endothelial cells under oxidative stress. Protein expression levels confirmed these results (Figure 4(c)). eNOS and Bax genes were upregulated when oxidative stress was induced using t-BuOOH stressor on endothelial cells. CD-NA treatment significantly reduced both eNOS and Bax gene expressions. This effect was not observed after AAPH ROS induction (Figures 4(c) and 4(d)). Additionally, CD-A treatment downregulates AKT and Casp3 gene expressions submitted to stress (Figure 4(c)). These results give some indications of a possible indirect CD-A cell protection against oxidative stress-induced apoptosis.

\section{Conclusion}

The use of carotenoids like antioxidants can assist the natural mechanisms of cells in neutralizing oxidative stress. Particularly, the xanthophyll carotenoid astaxanthin is of special interest, due to its ability to interact with free radicals as a chain-breaking molecule. Despite the positive results showed for astaxanthin in vivo treatment on induced oxidative stressrelated diseases, clinical trials have been disappointing due, among other factors, to the differences between the antioxidant systems of humans and rodents. Adequate carotenoid doses and determination of appropriate length treatments are not well established yet. In addition, several inconveniences have been attributed to their prone sensibility to degradation and lack of availability. Here, we showed the capacity of CD to enhance the astaxanthin solubility, improving the astaxanthin ability to reestablish the balance in the redox state of the cell. Additionally, the direct capacity of CD-A to inhibit the HUVEC and mitochondrial ROS and to reduce lipid peroxidation was demonstrated. Moreover, the CD-A indirect action to reduce ROS levels by reinforcing the Nrf2/HO-1/NQO1 endogenous antioxidant defenses was shown. The results presented in this research were performed in a human endothelial cell line and cannot be generalized to primary cells or animal models. Owing to these results, CD-A complex appears to be highly suitable for a posterior evaluation of its antioxidants capacities to regulate the ROS production in vivo, as an oxidative stress regulator. However, further research is necessary before considering the possibility of using this complex in human therapies.

\section{Additional Points}

Highlights

(1) CD improves the astaxanthin solubility without affecting its antioxidant scavenging capacities or compatibility.

(2) CD-A inhibits HUVEC cellular and mitochondrial ROS by reducing the disturbance in the redox state of the cell and the infiltration of lipid peroxidation radicals.

(3) CD-A complex can inhibit the oxidative stress in HUVEC by PTEN/AKT gene and protein expression and also enhance the $\mathrm{Nrf} 2 / \mathrm{HO}-1$ endogenous antioxidant defenses. 


\section{Conflicts of Interest}

The authors declare that they have no conflicts of interest.

\section{Acknowledgments}

The authors would like to thank Université Paris 13, Galilée Institute, and INSERM-LVTS U1148 Laboratory for the funding support.

\section{References}

[1] H. Sies, "Oxidative Stress: oxidants and antioxidants," Experimental Physiology, vol. 82, no. 2, pp. 291-295, 1997.

[2] E. R. Stadtman and R. L. Levine, "Protein oxidation," Annals of the New York Academy of Sciences, vol. 899, no. 1, pp. 191-208, 2000.

[3] D. P. Jones, "Redefining oxidative stress," Antioxidants \& Redox Signaling, vol. 8, no. 9-10, pp. 1865-1879, 2006.

[4] K. K. Griendling and G. A. FitzGerald, "Oxidative stress and cardiovascular injury: part I: basic mechanisms and in vivo monitoring of ROS," Circulation, vol. 108, no. 16, pp. 19121916, 2003.

[5] H. Mangge, K. Becker, D. Fuchs, and J. M. Gostner, "Antioxidants, inflammation and cardiovascular disease," World Journal of Cardiology, vol. 6, no. 6, pp. 462-477, 2014.

[6] G. Britton, "Structure and properties of carotenoids in relation to function," The FASEB Journal, vol. 9, no. 15, pp. 1551-1558, 1995.

[7] A. El-Agamey, G. M. Lowe, D. J. McGarvey et al., "Carotenoid radical chemistry and antioxidant/pro-oxidant properties," Archives of Biochemistry and Biophysics, vol. 430, no. 1, pp. 37-48, 2004.

[8] H. Tapiero, D. M. Townsend, and K. D. Tew, "The role of carotenoids in the prevention of human pathologies," Biomedicine \& Pharmacotherapy, vol. 58, no. 2, pp. 100-110, 2004.

[9] K. Yeum, G. Aldini, R. M. Russell, and N. I. Krinsky, "Antioxidant/pro-oxidant actions of carotenoids," Carotenoids, vol. 5, pp. 235-268, 2009.

[10] H. J. Forman, K. J. A. Davies, and F. Ursini, "How do nutritional antioxidants really work: nucleophilic tone and para-hormesis versus free radical scavenging in vivo," Free Radical Biology and Medicine, vol. 66, pp. 24-35, 2014.

[11] M. C. Crespo, J. Tomé-Carneiro, E. Burgos-Ramos et al., "One-week administration of hydroxytyrosol to humans does not activate phase II enzymes," Pharmacological Research, vol. 95-96, pp. 132-137, 2015.

[12] F. J. Pashkow, D. G. Watumull, and C. L. Campbell, “Astaxanthin: a novel potential treatment for oxidative stress and inflammation in cardiovascular disease," The American Journal of Cardiology, vol. 101, no. 10, pp. S58-S68, 2008.

[13] R. G. Fassett and J. S. Coombes, "Astaxanthin: a potential therapeutic agent in cardiovascular disease," Marine Drugs, vol. 9, no. 12, pp. 447-465, 2011.

[14] C. Caballo, E. M. Costi, M. D. Sicilia, and S. Rubio, "Determination of supplemental feeding needs for astaxanthin and canthaxanthin in salmonids by supramolecular solventbased microextraction and liquid chromatography-UV/VIS spectroscopy," Food Chemistry, vol. 134, no. 2, pp. 12441249, 2012.
[15] K. D. K. Nguyen, "Astaxanthin: a comparative case of synthetic vs. natural production," Chemical and Biomolecular Engineering Publications and Other Works, vol. 1, pp. 1-11, 2013.

[16] I. Higuera-Ciapara, L. Félix-Valenzuela, and F. M. Goycoolea, "Astaxanthin: a review of its chemistry and applications," Critical Reviews in Food Science and Nutrition, vol. 46, no. 2, pp. 185-196, 2006.

[17] F. Visioli and C. Artaria, "Astaxanthin in cardiovascular health and disease: mechanisms of action, therapeutic merits, and knowledge gaps," Food \& Function, vol. 8, no. 1, pp. 39-63, 2016.

[18] G. Hussein, U. Sankawa, H. Goto, K. Matsumoto, and H. Watanabe, "Astaxantin, a carotenoid with potentian in human health and nutrition," Journal of Natural Products, vol. 69, no. 3, pp. 443-449, 2006.

[19] H. McNulty, R. F. Jacob, and R. P. Mason, "Biologic activity of carotenoids related to distinct membrane physicochemical interactions," The American Journal of Cardiology, vol. 101, no. 10, pp. S20-S29, 2008.

[20] H. P. McNulty, J. Byun, S. F. Lockwood, R. F. Jacob, and R. P. Mason, "Differential effects of carotenoids on lipid peroxidation due to membrane interactions: X-ray diffraction analysis," Biochimica et Biophysica Acta (BBA)-Biomembranes, vol. 1768, no. 1, pp. 167-174, 2007.

[21] L. Zhang and H. Wang, "Multiple mechanisms of anti-cancer effects exerted by astaxanthin," Marine Drugs, vol. 13, no. 7, pp. 4310-4330, 2015.

[22] Y. Inoue, M. Shimazawa, R. Nagano et al., "Astaxanthin analogs, adonixanthin and lycopene, activate Nrf2 to prevent light-induced photoreceptor degeneration," Journal of Pharmacological Sciences, vol. 134, no. 3, pp. 147-157, 2017.

[23] T. Otsuka, M. Shimazawa, T. Nakanishi et al., "The protective effects of a dietary carotenoid, astaxanthin, against lightinduced retinal damage," Journal of Pharmacological Sciences, vol. 123, no. 3, pp. 209-218, 2013.

[24] R. R. Ambati, S. M. Phang, S. Ravi et al., "Astaxanthin: sources, extraction, stability, biological activities and its commercial applications-a review," Marine Drugs, vol. 12, no. 1, pp. 128-152, 2014.

[25] J. S. Coombes, J. E. Sharman, and R. G. Fassett, “Astaxanthin has no effect on arterial stiffness, oxidative stress, or inflammation in renal transplant recipients: a randomized controlled trial (the XANTHIN trial)," The American Journal of Clinical Nutrition, vol. 103, no. 1, pp. 283-289, 2016.

[26] N. Anarjan, H. Jafarizadeh-Malmiri, I. A. Nehdi, H. M. Sbihi, S. I. Al-Resayes, and C. P. Tan, "Effects of homogenization process parameters on physicochemical properties of astaxanthin nanodispersions prepared using a solvent-diffusion technique," International Journal of Nanomedicine, vol. 10, pp. 1109-1118, 2015.

[27] M. Nakao, M. Sumida, K. Katano, and H. Fukami, "Enzymatic synthesis of astaxanthin n-octanoic acid esters," Journal of Oleo Science, vol. 57, no. 7, pp. 371-374, 2008.

[28] Q. Dai, X. You, L. Che, F. Yu, C. Selomulya, and X. D. Chen, "An investigation in microencapsulating astaxanthin using a monodisperse droplet spray dryer," Drying Technology, vol. 31, no. 13-14, pp. 1562-1569, 2013.

[29] F. Tamjidi, M. Shahedi, J. Varshosaz, and A. Nasirpour, "Design and characterization of astaxanthin-loaded nanostructured lipid carriers," Innovative Food Science \& Emerging Technologies, vol. 26, pp. 366-374, 2014. 
[30] X. Chen, R. Chen, Z. Guo, C. Li, and P. Li, "The preparation and stability of the inclusion complex of astaxanthin with $\beta$ cyclodextrin," Food Chemistry, vol. 101, no. 4, pp. 15801584, 2007.

[31] C. Yuan, Z. Jin, X. Xu, H. Zhuang, and W. Shen, "Preparation and stability of the inclusion complex of astaxanthin with hydroxypropyl- $\beta$-cyclodextrin," Food Chemistry, vol. 109, no. 2, pp. 264-268, 2008.

[32] A. Krainev and D. J. Bigelow, “Comparison of 2,2'-azobis(2amidinopropane) hydrochloride (AAPH) and 2,2' -azobis(2,4-dimethylvaleronitrile) (AMVN) as free radical initiators: a spin-trapping study," Journal of the Chemical Society, Perkin Transactions, vol. 2, no. 4, pp. 747-754, 1996.

[33] Y. Yoshida, N. Itoh, Y. Saito, M. Hayakawa, and E. Niki, "Application of water-soluble radical initiator, 2,2' -azobis[2(2-imidazolin-2-yl)propane] dihydrochloride, to a study of oxidative stress," Free Radical Research, vol. 38, no. 4, pp. 375-384, 2004.

[34] S. I. Dikalov and D. G. Harrison, "Methods for detection of mitochondrial and cellular reactive oxygen species," Antioxidants \& Redox Signaling, vol. 20, no. 2, pp. 372-382, 2014.

[35] A. Ayala, M. F. Muñoz, and S. Argüelles, "Lipid peroxidation: production, metabolism, and signaling mechanisms of malondialdehyde and 4-hydroxy-2-nonenal," Oxidative Medicine and Cellular Longevity, vol. 2014, Article ID 360438, 31 pages, 2014.

[36] S. Dong, Y. Huang, R. Zhang, Z. Lian, S. Wang, and Y. Liu, "Inclusion complexes of astaxanthin with hydroxypropyl- $\beta$ cyclodextrin: parameters optimization, spectroscopic profiles, and properties," European Journal of Lipid Science and Technology, vol. 116, no. 8, pp. 978-986, 2014.

[37] R. Re, N. Pellegrini, A. Proteggente, A. Pannala, M. Yang, and C. Rice-Evans, "Antioxidant activity applying an improved ABTS radical cation decolorization assay," Free Radical Biology and Medicine, vol. 26, no. 9-10, pp. 1231-1237, 1999.

[38] E. Lien, S. Ren, H. Bui, and R. Wang, "Quantitative structure-activity relationship analysis of phenolic antioxidants," Free Radical Biology and Medicine, vol. 26, no. 3-4, pp. 285-294, 1999.

[39] Y. Sueishi, M. Ishikawa, D. Yoshioka et al., "Oxygen radical absorbance capacity (ORAC) of cyclodextrin-solubilized flavonoids, resveratrol and astaxanthin as measured with the ORAC-EPR method," Journal of Clinical Biochemistry and Nutrition, vol. 50, no. 2, pp. 127-132, 2012.

[40] X. J. Duan, W. W. Zhang, X. M. Li, and B. G. Wang, "Evaluation of antioxidant property of extract and fractions obtained from a red alga, Polysiphonia urceolata," Food Chemistry, vol. 95, no. 1, pp. 37-43, 2006.

[41] H. Wang and J. A. Joseph, "Quantifying cellular oxidative stress by dichlorofluorescein assay using microplate reader," Free Radical Biology and Medicine, vol. 27, no. 5-6, pp. 612616, 1999.

[42] A. Wojtala, M. Bonora, D. Malinska, P. Pinton, J. Duszynski, and M. R. Wieckowski, "Methods to monitor ROS production by fluorescence microscopy and fluorometry," Methods in Enzymology, vol. 542, pp. 243-262, 2014.

[43] M. Forkink, J. A. M. Smeitink, R. Brock, P. H. G. M. Willems, and W. J. H. Koopman, "Detection and manipulation of mitochondrial reactive oxygen species in mammalian cells," Biochimica et Biophysica Acta (BBA)-Bioenergetics, vol. 1797, no. 6-7, pp. 1034-1044, 2010.
[44] G. P. Drummen, L. C. van Liebergen, J. A. Op den Kamp, and J. A. Post, "C11-BODIPY ${ }^{581 / 591}$, an oxidation-sensitive fluorescent lipid peroxidation probe: (micro) spectroscopic characterization and validation of methodology," Free Radical Biology and Medicine, vol. 33, pp. 473-490, 2002.

[45] D. Qiu, Y.-C. Wu, W.-L. Zhu, H. Yin, and L.-T. Yi, "Identification of geometrical isomers and comparison of different isomeric samples of astaxanthin," Journal of Food Science, vol. 77, no. 9, pp. C934-C940, 2012.

[46] S. F. Lockwood, S. O. Malley, and G. L. Mosher, "Improved aqueous solubility of crystalline astaxanthin (sulfobutyl ether $\beta$-cyclodextrin)," Journal of Pharmaceutical Sciences, vol. 92, no. 4, pp. 922-926, 2003.

[47] I. Pfitzner, P. I. Francz, and H. K. Biesalski, "Carotenoid:methyl- $\beta$-cyclodextrin formulations: an improved method for supplementation of cultured cells," Biochimica et Biophysica Acta (BBA)-General Subjects, vol. 1474, no. 2, pp. 163$168,2000$.

[48] S. Kim, E. Cho, J. Yoo et al., " $\beta$-CD-mediated encapsulation enhanced stability and solubility of astaxanthin," Journal of Applied Biological Chemistry, vol. 53, no. 5, pp. 559-565, 2010.

[49] C. C. Winterbourn, "The challenges of using fluorescent probes to detect and quantify specific reactive oxygen species in living cells," Biochimica et Biophysica Acta (BBA) - General Subjects, vol. 1840, no. 2, pp. 730-738, 2014.

[50] J. Lü, P. H. Lin, Q. Yao, and C. Chen, "Chemical and molecular mechanisms of antioxidants: experimental approaches and model systems," Journal of Cellular and Molecular Medicine, vol. 14, no. 4, pp. 840-860, 2010.

[51] P. Régnier, J. Bastias, V. Rodriguez-Ruiz et al., "Astaxanthin from Haematococcus pluvialis prevents oxidative stress on human endothelial cells without toxicity," Marine Drugs, vol. 13, no. 5, pp. 2857-2874, 2015.

[52] R. Sowmya and N. M. Sachindra, "Evaluation of antioxidant activity of carotenoid extract from shrimp processing byproducts by in vitro assays and in membrane model system," Food Chemistry, vol. 134, no. 1, pp. 308-314, 2012.

[53] L. Jaime, I. Rodríguez-Meizoso, A. Cifuentes et al., "Pressurized liquids as an alternative process to antioxidant carotenoids' extraction from Haematococcus pluvialis microalgae," LWT-Food Science and Technology, vol. 43, no. 1, pp. 105$112,2010$.

[54] F. A. Reyes, J. A. Mendiola, E. Ibañez, and J. M. Del Valle, "Astaxanthin extraction from Haematococcus pluvialis using $\mathrm{CO}_{2}$-expanded ethanol," Journal of Supercritical Fluids, vol. 92, pp. 75-83, 2014.

[55] J. Chen, S. Wang, L. Ma, W. Zheng, and Q. Li, "Study on antioxidant activity of astaxanthin," Acta Nutrimenta Sinica, vol. 29, pp. 163-165, 2007.

[56] Y. M. A. Naguib, "Antioxidant activities of astaxanthin and related carotenoids," Journal of Agricultural and Food Chemistry, vol. 48, no. 4, pp. 1150-1154, 2000.

[57] K. L. Wolfe and R. H. Liu, "Structure-activity relationships of flavonoids in the cellular antioxidant activity assay," Journal of Agricultural and Food Chemistry, vol. 56, no. 18, pp. 84048411, 2008.

[58] S. Tan, K. Ladewig, Q. Fu, A. Blencowe, and G. G. Qiao, "Cyclodextrin-based supramolecular assemblies and hydrogels: recent advances and future perspectives," Macromolecular Rapid Communications, vol. 35, no. 13, pp. 11661184, 2014. 
[59] E. Sieniawska, T. Baj, R. Sawicki et al., "LC-QTOF-MS analysis and activity profiles of popular antioxidant dietary supplements in terms of quality control," Oxidative Medicine and Cellular Longevity, vol. 2017, Article ID 8692516, 11 pages, 2017.

[60] D. R. Day, S. Jabaiah, R. S. Jacobs, and R. D. Little, "Cyclodextrin formulation of the marine natural product pseudopterosin A uncovers optimal pharmacodynamics in proliferation studies of human umbilical vein endothelial cells," Marine Drugs, vol. 11, no. 9, pp. 3258-3271, 2013.

[61] A. Fernández-Ferreiro, N. Fernández Bargiela, M. S. Varela et al., "Cyclodextrin-polysaccharide-based, in situ-gelled system for ocular antifungal delivery," Beilstein Journal of Organic Chemistry, vol. 10, pp. 2903-2911, 2014.

[62] R. Mateen and T. Hoare, "Injectable, in situ gelling, cyclodextrin-dextran hydrogels for the partitioning-driven release of hydrophobic drugs," Journal of Materials Chemistry B, vol. 2, no. 32, pp. 5157-5167, 2014.

[63] S. Nagaraj, M. G. Rajaram, P. Arulmurugan et al., "Antiproliferative potential of astaxanthin-rich alga Haematococcus pluvialis Flotow on human hepatic cancer (HepG2) cell line," Biomedicine \& Preventive Nutrition, vol. 2, pp. 149-153, 2012.

[64] C. McCarthy and L. C. Kenny, "Therapeutically targeting mitochondrial redox signalling alleviates endothelial dysfunction in preeclampsia," Scientific Reports, vol. 6, no. 1, article 32683, 2016.

[65] Q. He, N. Harris, J. Ren, and X. Han, "Mitochondria-targeted antioxidant prevents cardiac dysfunction induced by tafazzin gene knockdown in cardiac myocytes," Oxidative Medicine and Cellular Longevity, vol. 2014, Article ID 654198, 12 pages, 2014.

[66] O. I. Aruoma, B. Halliwell, B. M. Hoey, and J. Butler, "The antioxidant action of $\mathrm{N}$-acetylcysteine: its reaction with hydrogen peroxide, hydroxyl radical, superoxide, and hypochlorous acid," Free Radical Biology and Medicine, vol. 6, no. 6, pp. 593597, 1989.

[67] C. Sen Chang, C. L. Chang, and G. H. Lai, "Reactive oxygen species scavenging activities in a chemiluminescence model and neuroprotection in rat pheochromocytoma cells by astaxanthin, beta-carotene, and canthaxanthin," The Kaohsiung Journal of Medical Sciences, vol. 29, no. 8, pp. 412-421, 2013.

[68] B. Alves Guerra and R. Otton, "Impact of the carotenoid astaxanthin on phagocytic capacity and ROS/RNS production of human neutrophils treated with free fatty acids and high glucose," International Immunopharmacology, vol. 11, no. 12, pp. 2220-2226, 2011.

[69] T. Hofer, T. E. Eriksen, E. Hansen et al., "Cellular and chemical assays for discovery of novel antioxidants in marine organisms," in Studies on Experimental Models. Oxidative Stress in Applied Basic Research and Clinical Practice, S. Basu and L. Wiklund, Eds., pp. 637-657, Humana Press, Totowa, NJ, USA, 2011.

[70] X.-L. Xue, X.-D. Han, Y. Li et al., “Astaxanthin attenuates total body irradiation-induced hematopoietic system injury in mice via inhibition of oxidative stress and apoptosis," Stem Cell Research \& Therapy, vol. 8, no. 1, p. 7, 2017.

[71] R. R. Nazarewicz, A. Bikineyeva, and S. Dikalov, "Rapid and specific measurements of superoxide using fluorescence spectroscopy," Journal of Biomolecular Screening, vol. 18, no. 4, pp. 498-503, 2013.

[72] P. Lobos, B. Bruna, A. Cordova et al., "Astaxanthin protects primary hippocampal neurons against noxious effects of $\mathrm{A} \beta$ - oligomers," Neural Plasticity, vol. 2016, Article ID 3456783, 13 pages, 2016.

[73] N. Apostolova and V. M. Victor, "Molecular strategies for targeting antioxidants to mitochondria: therapeutic implications," Antioxidants \& Redox Signaling, vol. 22, no. 8, pp. 686-729, 2015.

[74] K. R. Gibson, T. J. Winterburn, F. Barrett, S. Sharma, S. M. MacRury, and I. L. Megson, "Therapeutic potential of Nacetylcysteine as an antiplatelet agent in patients with type-2 diabetes," Cardiovascular Diabetology, vol. 10, no. 1, p. 43, 2011.

[75] A. Gomes, E. Fernandes, and J. L. F. C. Lima, "Fluorescence probes used for detection of reactive oxygen species," Journal of Biochemical and Biophysical Methods, vol. 65, no. 2-3, pp. 45-80, 2005.

[76] R. L. Prior, X. Wu, and K. Schaich, "Standarized methods for the determination of antioxidant capacity and phenolics in foods and dietary supplements," Journal of Agricultural and Food Chemistry, vol. 53, no. 10, pp. 4290-4302, 2005.

[77] P. Wardman, "Fluorescent and luminescent probes for measurement of oxidative and nitrosative species in cells and tissues: progress, pitfalls, and prospects," Free Radical Biology and Medicine, vol. 43, no. 7, pp. 995-1022, 2007.

[78] G. E. Mann, "Nrf2-mediated redox signalling in vascular health and disease," Free Radical Biology and Medicine, vol. 75, p. S1, 2014.

[79] T.-S. Lee and L.-Y. Chau, "Heme oxygenase-1 mediates the anti-inflammatory effect of interleukin-10 in mice," Nature Medicine, vol. 8, no. 3, pp. 240-246, 2002.

[80] M.-L. Wu, Y.-C. Ho, and S.-F. Yet, "A central role of heme oxygenase-1 in cardiovascular protection," Antioxidants \& Redox Signaling, vol. 15, no. 7, pp. 1835-1846, 2011.

[81] A. T. Dinkova-Kostova and P. Talalay, "NAD(P)H:quinone acceptor oxidoreductase 1 (NQO1), a multifunctional antioxidant enzyme and exceptionally versatile cytoprotector," Archives of Biochemistry and Biophysics, vol. 501, no. 1, pp. 116-123, 2010.

[82] A. Prawan, B. Buranrat, U. Kukongviriyapan, B. Sripa, and V. Kukongviriyapan, "Inflammatory cytokines suppress $\mathrm{NAD}(\mathrm{P}) \mathrm{H}$ :quinone oxidoreductase- 1 and induce oxidative stress in cholangiocarcinoma cells," Journal of Cancer Research and Clinical Oncology, vol. 135, no. 4, pp. 515-522, 2009.

[83] A. Alexoudi, S. Zachaki, C. Stavropoulou et al., "Combined GSTP1 and NQO1 germline polymorphisms in the susceptibility to multiple sclerosis," The International Journal of Neuroscience, vol. 125, no. 1, pp. 32-37, 2015.

[84] Y. Guo, S. Yu, C. Zhang, and A. N. T. Kong, "Epigenetic regulation of Keap1-Nrf2 signaling," Free Radical Biology and Medicine, vol. 88, pp. 337-349, 2015.

[85] Y. Yang, M. Bae, B. Kim, Y.-K. Park, S. I. Koo, and J.-Y. Lee, "Astaxanthin prevents and reverses the activation of mouse primary hepatic stellate cells," The Journal of Nutritional Biochemistry, vol. 29, pp. 21-26, 2016.

[86] Q. Wu, X. S. Zhang, H. D. Wang et al., "Astaxanthin activates nuclear factor erythroid-related factor 2 and the antioxidant responsive element (Nrf2-ARE) pathway in the brain after subarachnoid hemorrhage in rats and attenuates early brain injury," Marine Drugs, vol. 12, no. 12, pp. 61256141, 2014.

[87] J. Dose, S. Matsugo, H. Yokokawa et al., "Free radical scavenging and cellular antioxidant properties of astaxanthin," 
International Journal of Molecular Sciences, vol. 17, no. 1, pp. 1-14, 2016.

[88] Z. Li, X. Dong, H. Liu et al., “Astaxanthin protects ARPE19 cells from oxidative stress via upregulation of Nrf2regulated phase II enzymes through activation of PI3K/Akt," Molecular Vision, vol. 19, pp. 1656-1666, 2013, http://www. molvis.org/molvis/v19/1656/.

[89] L. Pan, Y. Zhou, X. F. Li, Q. J. Wan, and L. H. Yu, "Preventive treatment of astaxanthin provides neuroprotection through suppression of reactive oxygen species and activation of antioxidant defense pathway after stroke in rats," Brain Research Bulletin, vol. 130, pp. 211-220, 2017.

[90] A. Nakanishi, Y. Wada, Y. Kitagishi, and S. Matsuda, "Link between PI3K/AKT/PTEN Pathway and NOX Proteinin Diseases," Aging and Disease, vol. 5, no. 3, pp. 203-211, 2014.

[91] Y. Kureishi, Z. Luo, I. Shiojima et al., "The HMG-CoA reductase inhibitor simvastatin activates the protein kinase Akt and promotes angiogenesis in normocholesterolemic animals," Nature Medicine, vol. 6, no. 9, pp. 1004-1010, 2010.

[92] C. M. E. I. Wang, X. L. A. N. Cai, and Q. P. Wen, “Astaxanthin reduces isoflurane-induced neuroapoptosis via the PI3K/Akt pathway," Molecular Medicine Reports, vol. 13, no. 5, pp. 4073-4078, 2016. 


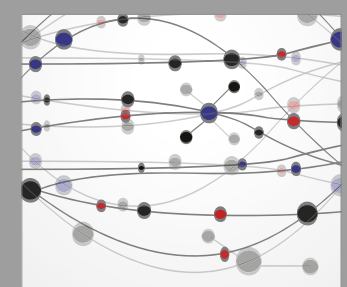

The Scientific World Journal
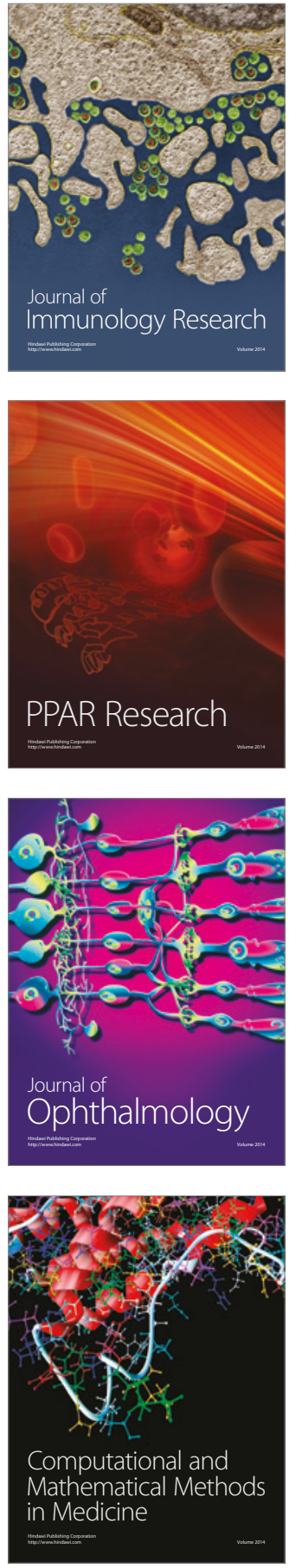

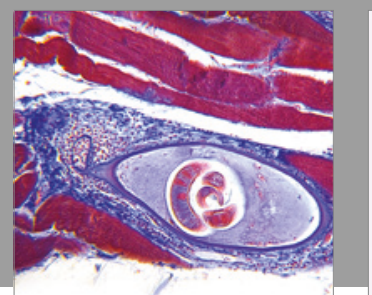

Gastroenterology Research and Practice
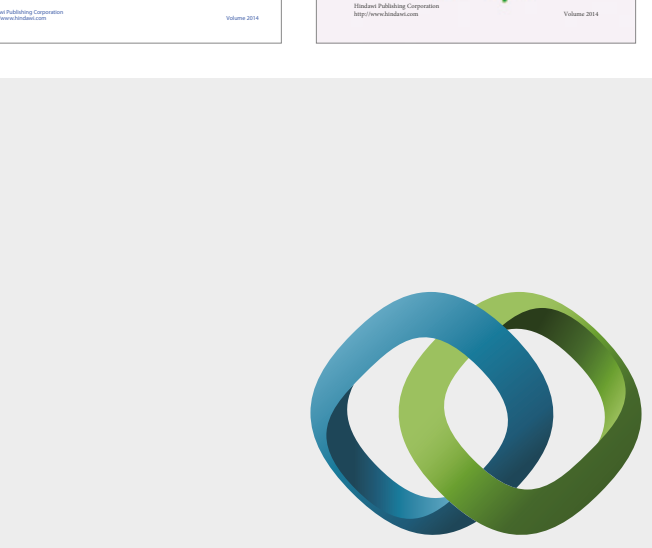

\section{Hindawi}

Submit your manuscripts at

https://www.hindawi.com
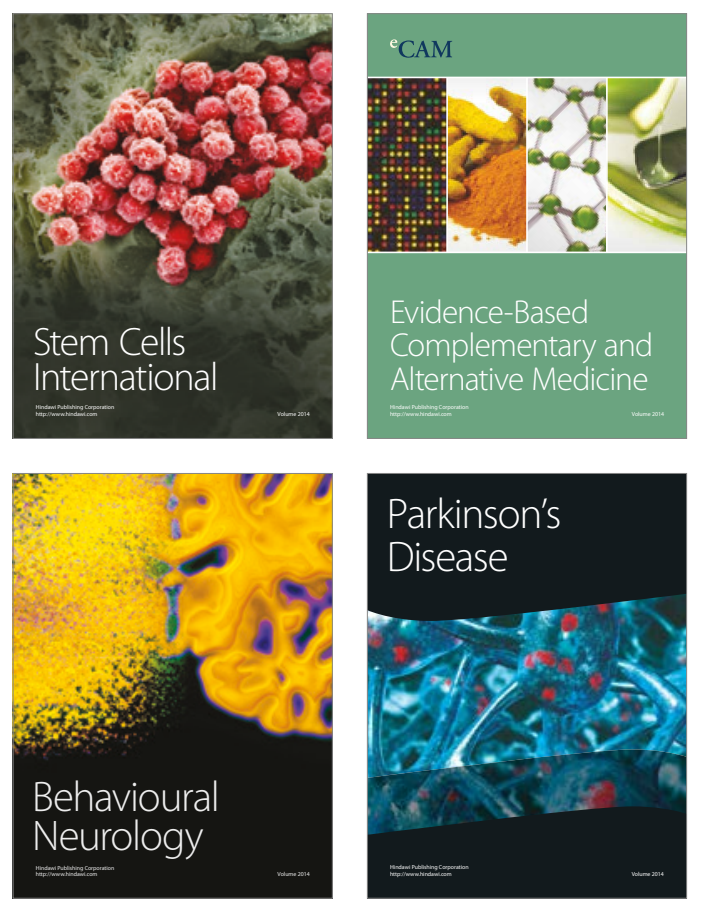
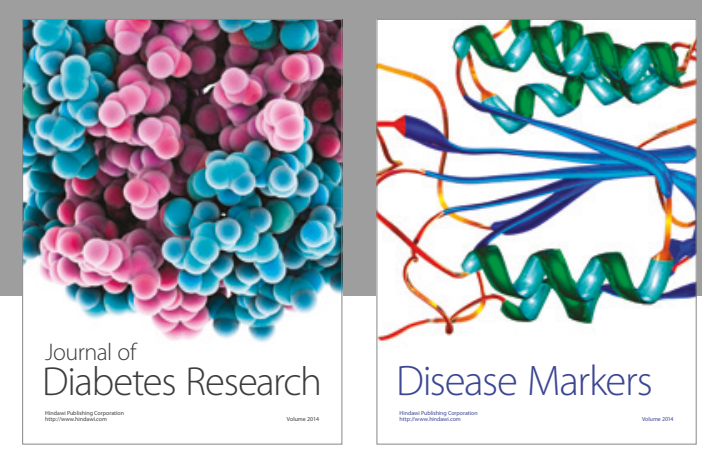

Disease Markers
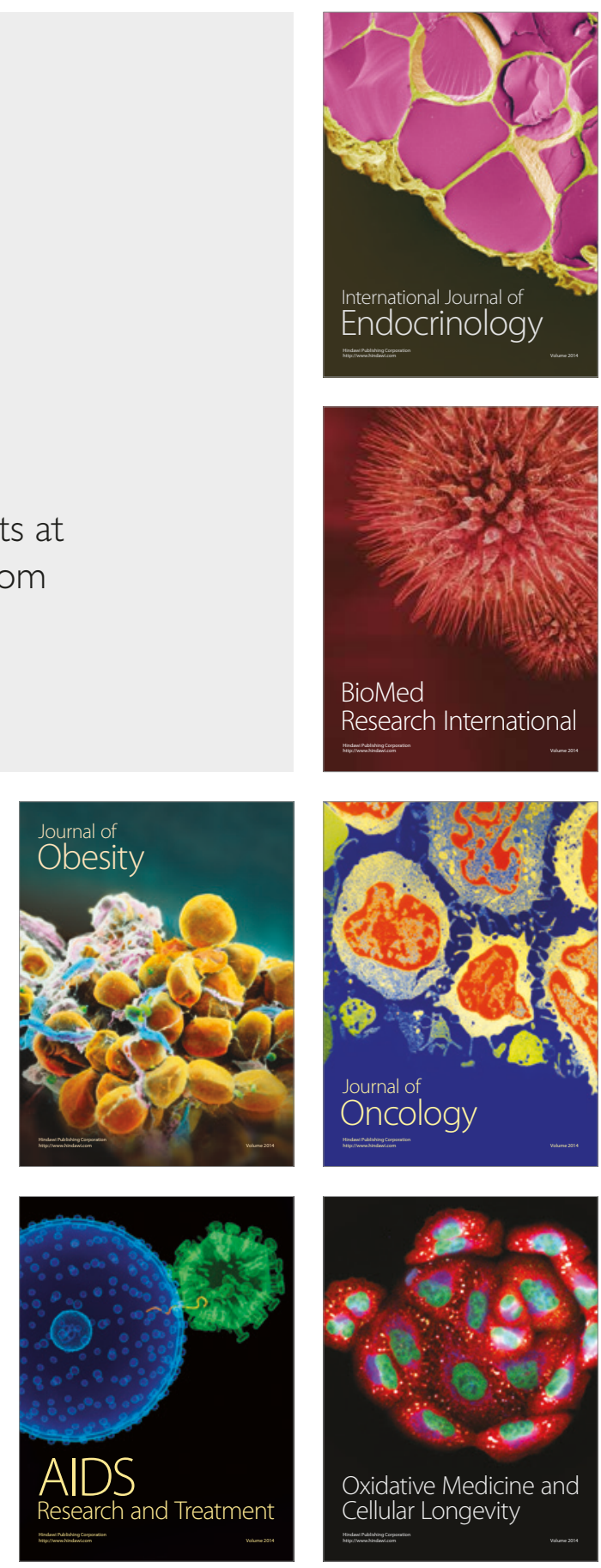